Dear author,

Please note that changes made in the online proofing system will be added to the article before publication but are not reflected in this PDF.

We also ask that this file not be used for submitting corrections. 


\title{
An experimental and modeling study of the ignition of dimethyl carbonate in shock tubes and rapid compression machine
}

\author{
Katiuska Alexandrino ${ }^{a, b, *}$, María U. Alzueta ${ }^{b}$, Henry J. Currana \\ a Combustion Chemistry Centre, School of Chemistry, NUI Galway, Ireland \\ ${ }^{\mathrm{b}}$ Aragón Institute of Engineering Research (I3A), Department of Chemical and Environmental Engineering, University of Zaragoza, 50018 Zaragoza, Spain
}

\section{A R T I C L E I N F O}

\section{Article history:}

Received 14 July 2017

Revised 22 August 2017

Accepted 2 October 2017

Available online $\mathrm{xxx}$

\section{Keywords:}

Shock tube

Rapid compression machine

Dimethyl carbonate

Oxidation

Kinetic model

\begin{abstract}
A B S T R A C T
Ignition delay times of dimethyl carbonate DMC were measured using low- and high-pressure shock tubes and in a rapid compression machine (RCM). In this way, the effect of fuel concentration $(0.75 \%$ and $1.75 \%)$, pressure $(2.0,20$, and $40 \mathrm{~atm})$ and equivalence ratio $(0.5,1.0,2.0)$ on ignition delay times was studied experimentally and by modeling. Experiments cover the temperature range of (795-1585 K). Several models from literature were used to perform simulations, thus their performances to predict the present experimental data was examined. Furthermore, the effect of the thermodynamic data of the $\mathrm{CH}_{3} \mathrm{O}(\mathrm{C}=\mathrm{O}) \mathrm{O}$ radical species and the fuel consumption reaction $\mathrm{CH}_{3} \mathrm{O}(\mathrm{C}=\mathrm{O}) \mathrm{OCH}_{3} \rightleftarrows \mathrm{CH}_{3} \mathrm{O}(\mathrm{C}=\mathrm{O}) \dot{\mathrm{O}}+\mathrm{CH}_{3}$, on the simulations of the ignition delay times of DMC was analyzed using the different models. Reaction path and sensitivity analyses were carried out with the final model to present an in-depth analysis of the oxidation of DMC under the different conditions studied. The final model used AramcoMech 2.0 as the base mechanism and included a DMC sub-mechanism available in literature to which the reaction $\mathrm{CH}_{3} \mathrm{O}(\mathrm{C}=\mathrm{O}) \mathrm{OCH}_{3} \rightleftarrows \mathrm{CH}_{3} \mathrm{O}(\mathrm{C}=\mathrm{O}) \dot{\mathrm{O}}+\mathrm{CH}_{3}$ was modified. Good agreement is observed between calculated and experimental data. The model was also validated using available experimental data from flow reactors and opposed flow diffusion and laminar premixed flames studies showing an overall good performance.
\end{abstract}

๑ 2017 The Combustion Institute. Published by Elsevier Inc. All rights reserved.

\section{Introduction}

Dimethyl carbonate $\left(\mathrm{CH}_{3} \mathrm{O}(\mathrm{C}=\mathrm{O}) \mathrm{OCH}_{3}, \mathrm{DMC}\right)$, a non-toxic and non-corrosive carbonate ester with no $\mathrm{C}-\mathrm{C}$ bonds and containing $53 \%$ oxygen by weight, has been identified as a suitable fuel compound to be added to diesel fuel to reduce PM emissions without affecting $\mathrm{NO}_{\mathrm{X}}$ emissions [e.g., 1]. Even though it is $100 \%$ miscible with diesel fuel, it must be used as a blended fuel in diesel engines due to its low cetane number (35-36), low calorific value $(15.78 \mathrm{MJ} / \mathrm{kg})$, and high latent heat of evaporation $(369 \mathrm{~kJ} / \mathrm{kg})[2,3]$.

To contribute to the development of detailed chemical kinetic models to describe the combustion characteristics of DMC, a thorough understanding of its combustion chemistry is needed. These chemical kinetic models can be used in conjunction with computational fluid dynamics (CFD) codes, with the necessary simplifications, to simulate the physical and chemical processes in engines, leading to optimal engine efficiency with minimal emissions.

\footnotetext{
* Corresponding author at: Aragón Institute of Engineering Research (I3A), Department of Chemical and Environmental Engineering, University of Zaragoza, C/ Mariano Esquillor, s/n, 50018 Zaragoza, Spain.

E-mail address: katyalex@unizar.es (K. Alexandrino).
}

To this end, studies addressing the thermal decomposition [4-6], photolysis [7] and oxidation of DMC have been reported in the literature.

Sinha and Thomson [8] measured species concentrations across DMC/air and propane/DMC/air opposed flow diffusion flames. Formaldehyde was found to be an important intermediate species in the DMC flame, and the presence of oxygen on the central carbon in DMC favors breakage of the $\mathrm{O}-\mathrm{CO}$ bond which results in very low levels of formation of methane, ethane, ethylene, and acetylene. Glaude et al. [9] developed the first chemical kinetic sub-mechanism for DMC conversion, which was incorporated into a previously developed chemical kinetic mechanism for dimethoxy methane (DMM) and dimethyl ether (DME) [10,11]. The predicted composition profiles using this model were in reasonable agreement with the measured species profiles from Sinha and Thomson [8].

Chen et al. [12] investigated the oxidation of $\mathrm{n}$-heptane $/ \mathrm{DMC} / \mathrm{O}_{2} / \mathrm{Ar}$ mixtures in a laminar pre-mixed lowpressure (30Torr) flame, at an equivalence ratio of 1.16 , using synchrotron photoionization and molecular-beam mass spectrometry (PI-MBMS) techniques. Measured and simulated mole fraction profiles of major and intermediate species were compared. The 
calculations were performed using a model which includes the DMM and DMC sub-mechanisms from the model developed by Glaude et al. [9]. The predicted concentrations of flame species agree reasonably well with the measured results. The authors observed an early production of $\mathrm{CO}_{2}$ in both the measured and modeling results which is suggested to occur mainly due to the decomposition of methoxy formyl $\left(\mathrm{CH}_{3} \mathrm{O} \dot{\mathrm{C}}=0\right)$ radicals.

Peukert et al. [13,14] studied the high temperature thermal decomposition of DMC, and its interaction with $\dot{\mathrm{H}}$ and $\mathrm{O}$ atoms, using the shock tube technique in conjunction with master equation analysis. Bardin et al. [15] measured laminar burning velocities of DMC/air flames at initial gas mixture temperatures of 298,318 , 338 , and $358 \mathrm{~K}$. These results were simulated using the model developed by Glaude et al. [9],and it was found that the model significantly over-predicted the measured laminar burning velocities.

More recently, $\mathrm{Hu}$ et al. [16] measured ignition delay times of DMC oxidation in a shock tube at high temperatures (1100$1600 \mathrm{~K})$, at different pressures $(1.2-10 \mathrm{~atm})$, fuel concentrations $(0.5-2.0 \%)$ and equivalence ratios $(\varphi=0.5-2.0)$. A chemical kinetic model, based on the modification of the DMC sub-mechanism from Glaude et al. [9] and the AramcoMech 1.3 mechanism [17], was proposed to describe the ignition delay times of DMC. The measured ignition delay times from this work, as well as the DMC/air opposed diffusion flame data reported by Sinha and Thomson [8], were compared with model calculations showing good agreement.

Sun et al. [18] investigated both pyrolysis of DMC in a flow reactor at different pressures $(40,200$ and $1040 \mathrm{mbar}$ ) and its oxidation in laminar premixed low-pressure $\mathrm{DMC} / \mathrm{O}_{2} / \mathrm{Ar}$ flames with equivalence ratios of 1.0 and 1.5 , at 25 and 30 Torr, respectively. A detailed kinetic model for DMC pyrolysis and combustion, based on a new sub-mechanism for DMC conversion and the AramcoMech 1.3 mechanism [17], was proposed. This model was validated using the experimental data obtained by Sun et al. [18] and with the opposed flow flame [8], burning velocities [15] and shock tube [16] experimental data from the literature. A more detailed description of these three DMC sub-mechanisms $[9,16,18]$ is further shown in Section 3.

Most recently, Alzueta et al. [19] carried out an atmospheric flow reactor study of DMC oxidation in the absence and presence of NO in the temperature range $700-400 \mathrm{~K}$ at $\varphi=0.028,1.00$, 1.43, and 3.33. It was found that, in the DMC-NO interaction, the fuel-rich conditions contribute slightly to the net reduction of $\mathrm{NO}_{\mathrm{x}}$. A detailed kinetic model, based on the DMC sub-mechanism from Glaude et al. [9] and a core mechanism described and updated by the authors [20-24], was proposed. With this model, these authors evaluated the impact of the thermodynamic data on the modeling results, finding that the enthalpy of formation of the so-called DMC radical $\mathrm{CH}_{3} \mathrm{O}(\mathrm{C}=0) \mathrm{O}$ significantly influences the DMC conversion results. The influence of the thermodynamics of the $\mathrm{CH}_{3} \mathrm{O}(\mathrm{C}=\mathrm{O}) \mathrm{O}$ radicals species on our current ignition delay time measurements will be further discussed in Section 4. Alzueta et al. [19] also performed one DMC pyrolysis experiment in an atmospheric flow reactor in order to determine its capacity to form soot, which was found to be very low. Following this work, Alexandrino et al. [25] studied the sooting propensity of DMC through pyrolysis experiments in an atmospheric flow reactor in the temperature range 1075-1475 K and inlet DMC concentrations of 33,333 and $50,000 \mathrm{ppm}$. It was confirmed that DMC has a very low tendency to form soot, even when compared with ethanol, because the formation of $\mathrm{CO}$ and $\mathrm{CO}_{2}$ is favored, and thus few carbon atoms are available for soot formation. The formation of $\mathrm{CO}_{2}$ is highly favored by the decomposition of the $\mathrm{CH}_{3} \mathrm{O} \dot{\mathrm{C}}=\mathrm{O}$ and $\mathrm{CH}_{3} \mathrm{O}(\mathrm{C}=\mathrm{O}) \dot{\mathrm{O}}$ radicals. Soot reactivity and characterization by instrumental techniques was also considered, showing that the higher temperature and the inlet DMC concentration of soot formation, the lower the reactivity of the soot.
Table 1

Composition of DMC mixtures studied in the low-pressure shock tube.

\begin{tabular}{llllll}
\hline Mix. & $P_{5}{ }^{\mathrm{a}}(\mathrm{atm})$ & $\varphi$ & $\mathrm{DMC}($ mole\%) & $\mathrm{O}_{2}$ (mole\%) & $\mathrm{Ar}(\mathrm{mole} \%)$ \\
\hline $1 \mathrm{~A}$ & 2 & 0.5 & 0.75 & 4.5 & 94.75 \\
$2 \mathrm{~A}$ & 2 & 1 & 0.75 & 2.25 & 97 \\
$3 \mathrm{~A}$ & 2 & 2 & 0.75 & 1.12 & 98.12 \\
$4 \mathrm{~A}$ & 2 & 0.5 & 1.75 & 10.5 & 87.75 \\
$5 \mathrm{~A}$ & 2 & 1 & 1.75 & 5.25 & 93 \\
$6 \mathrm{~A}$ & 2 & 2 & 1.75 & 2.62 & 95.62 \\
\hline
\end{tabular}

a $P_{5}$ is the pressure behind the reflected shock wave.

To our knowledge, to date the work of Hu et al. [16] is unique in studying ignition delay times for DMC oxidation. Although that work covered a wide range of equivalence ratios, DMC concentrations and pressures, more experimental data for the ignition of DMC are needed to develop and validate chemical kinetic models to accurately describe DMC combustion. Keeping this in mind, the aims of this work are: 1) to study ignition delay times of DMC under new experimental conditions, and thereby extend the available experimental data of DMC oxidation. In particular, lowand high-pressure shock tubes were used and, for the first time, a rapid compression machine was used in order to extend the high-pressure shock tube data of DMC to lower temperatures; 2) to compare the performance of the different models for DMC conversion available in literature to predict the measured ignition delay times of this work. This also includes the analysis of the effect of changing the thermodynamic of the $\mathrm{CH}_{3} \mathrm{O}(\mathrm{C}=\mathrm{O}) \dot{\mathrm{O}}$ radicals species and reaction kinetics on the modeling calculations. The goal is to find a model that best predicts our experimental ignition delay times and also various other experimental targets including flow reactors and opposed flow diffusion and laminar premixed flames; and 3) to perform the chemical interpretation of the effect of the DMC concentration, pressure and equivalence ratio on measured ignition delay times through rate of production and sensitivity analyses.

\section{Experimental}

Shock tube and rapid compression machine ignition delay time data were obtained using the facilities at the National University of Ireland Galway (NUIG). The full list of mixtures studied and their compositions are provided in Tables 1 and 2. Experiments with stoichiometric and fuel-rich mixtures compressed at 40 atm could not be performed in the rapid compression machine due to the high rate of heat release during ignition, which damaged the pressure transducer used to monitor the pressure.

DMC liquid (99\% pure, Sigma-Aldrich) was used without further purification. $\mathrm{O}_{2}$, $\mathrm{Ar}$ and $\mathrm{N}_{2}$ cylinders were supplied by BOC at high purity (99.5\%). Mixtures were prepared in an evacuated and heated (348 K) stainless steel mixing tank at each facility, using the partial pressure method. The fuel was injected via an injection port on the tank using a gas-tight syringe, followed by the addition of $\mathrm{O}_{2}$ and finally the diluent $\left(\mathrm{Ar}\right.$ or $\mathrm{N}_{2}$ ). For all conditions, the partial pressure of the fuel was maintained at a value less than one-third that of its saturated vapour pressure at the tank temperature to avoid fuel condensation. Each mixture was allowed to homogenize overnight before use. The uncertainty in mixture concentrations is estimated to be $\pm 2 \%$. The experimental procedure and facilities to determine the ignition delay time data are explained briefly below.

\subsection{Low-pressure shock tube}

To measure the ignition delay time of $\mathrm{DMC} / \mathrm{O}_{2} / \mathrm{Ar}$ mixtures at high temperatures $(T=1220-1585 \mathrm{~K})$ and at low pressure $(P=2$ atm) (mixtures in Table 1), a low-pressure shock tube (LPST), 


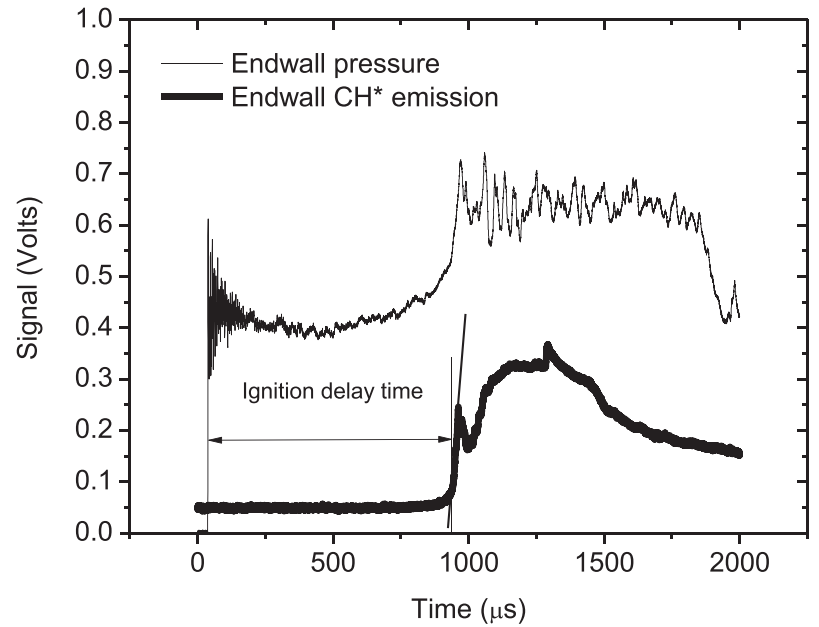

Fig. 1. Endwall pressure and $\mathrm{CH}^{*}$ emission traces with the definition of ignition delay time in the low-pressure shock tube. Example for $1.75 \% \mathrm{DMC}, \varphi=1, P=2 \mathrm{~atm}$ (mixture $5 \mathrm{~A}$ in Table 1 ), $T=1303 \mathrm{~K}$.

described previously by Smith et al. [26], was used. Briefly, the stainless steel tube consists of a $63 \mathrm{~cm}$ long and $52 \mathrm{~cm}$ diameter barrel-shaped driver section, which is coupled to a $6.22 \mathrm{~m}$ long driven section (internal diameter of $10.24 \mathrm{~cm}$ ). The two sections are separated using a polycarbonate diaphragm. Helium (99.99\%, BOC Ireland) was used as the driver gas. Five PCB $113 B 24$ pressure transducers, located in the driven section, were used to determine the shock velocity at the endwall, taking account of shock wave attenuation by linearly extrapolating the five velocities to the endwall. The endwall pressure was detected using a Kistler (603B) pressure transducer. Light emission, which was emitted from excited $\mathrm{CH}^{*}$ radicals, was detected using a photo-detector (Thorlabs Inc. PDA55-EC) and a narrow band-pass filter centered at $430 \mathrm{~nm}$, through a fused silica window embedded in the endwall. All pressure and $\mathrm{CH}^{*}$ emission signals were recorded using two Handyscope HS4 digital oscilloscopes. The chemical equilibrium program (GasEq) [27] was used to calculate the reflected shock temperature $\left(T_{5}\right)$ and pressure $\left(P_{5}\right)$ of each shock knowing the test gas composition, shock wave velocity, initial pressure of test gas and initial temperature of the gas. The uncertainties of the reflected shock temperature is estimated to be $\pm 1 \mathrm{~K}$.

The ignition delay time was defined as the time interval between the rise in pressure due to the arrival of the shock wave at the endwall and that due to fuel ignition. Fuel ignition is visible by following the increase in light emission (in this case in form of $\mathrm{CH}^{*}$ emission) due to the ignition event. In this way, onset of ignition was defined by extrapolating the maximum slope of $\mathrm{CH}^{*}$ emission to the baseline, as indicated in Fig. 1. The uncertainty in the measured ignition delay times was determined to be $\pm 15 \%$, due to the uncertainties in the conditions behind the reflected shock wave.

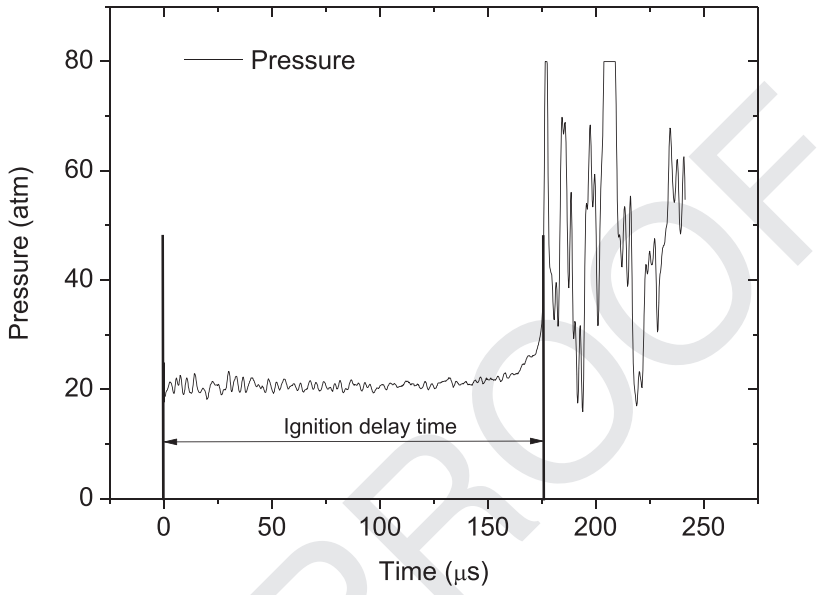

Fig. 2. Pressure trace with the definition of the ignition delay time in the highpressure shock tube. Example for $\varphi=1, P=40$ atm (mixture $5 \mathrm{~B}$ in Table 2), $T=1199 \mathrm{~K}$.

Uncertainties in the mole fractions of reactants are minimal $(<5 \%)$ as high accuracy digital pressure gauges were used.

185 186

\subsection{High-pressure shock tube}

The ignition delay times of DMC/air mixtures at high temperatures $(T=950-1400 \mathrm{~K})$ and high pressures $(P=20$ and $40 \mathrm{~atm})$ (mixtures $1 \mathrm{~B}-6 \mathrm{~B}$ in Table 2) were measured in a heated highpressure shock tube (HPST) with driver and driven section lengths of 3.0 and $5.7 \mathrm{~m}$, respectively, and an internal diameter of $63.5 \mathrm{~mm}$, described in detail previously [28]. A $3 \mathrm{~cm}$ double-diaphragm section separated the driver and the driven sections. Pre-scored aluminium plates were used as diaphragms.

The driver section was pressurized with pure helium or with a helium-nitrogen mixture, the later to achieve a tailored condition in order to obtain longer test time [29,30]. Approximately half of the total driver pressure was filled into the middle-section, acting as a buffer between the much lower initial test gas pressure and the much higher driver gas pressure.

Six pressure transducers (PCB 113B24), mounted flush to the interior wall of the heated driven section, were used to determine the shock velocity at the endwall. In the same way, as that in the low-pressure shock tube, this value was used to calculate the temperature and pressure behind the reflected shock wave using GasEq [27]. The pressure at the driven section endwall, used to measure the ignition delay time, was monitored using a Kistler 603B pressure transducer. Pressure traces (example in Fig. 2) were obtained using two Handyscope HS4 digital oscilloscopes. The ignition delay time was defined as the time interval between the pressure rise due to the arrival of the shock wave at the endwall and the maximum rate of pressure rise due to the ignition event.

Table 2

Composition of DMC mixtures studied in the high-pressure shock tube (HPST) and rapid compression machine (RCM).

\begin{tabular}{|c|c|c|c|c|c|c|c|c|c|}
\hline$P_{5}$ or $P_{\mathrm{C}^{\mathrm{a}}}(\mathrm{atm})$ & $\varphi$ & Mix. & \multicolumn{3}{|l|}{ HPST } & Mix. & \multicolumn{3}{|l|}{$\mathrm{RCM}$} \\
\hline \multirow[t]{2}{*}{20} & 0.5 & $1 \mathrm{~B}$ & 3.38 & 20.30 & 76.32 & $1 C$ & 3.38 & 20.30 & 76.32 \\
\hline & 2 & $3 \mathrm{~B}$ & 12.28 & 18.43 & 69.29 & $3 C$ & 12.28 & 18.43 & 69.29 \\
\hline \multirow[t]{2}{*}{40} & 0.5 & $4 \mathrm{~B}$ & 3.38 & 20.30 & 76.32 & $4 C$ & 3.38 & 20.30 & 76.32 \\
\hline & 1 & $5 B$ & 6.54 & 19.63 & 73.82 & & - & - & - \\
\hline
\end{tabular}

\footnotetext{
a $P_{5}$ is the pressure behind the reflected shock wave (in the HPST) and $P_{c}$ is the compressed gas pressure (in the RCM).
} 


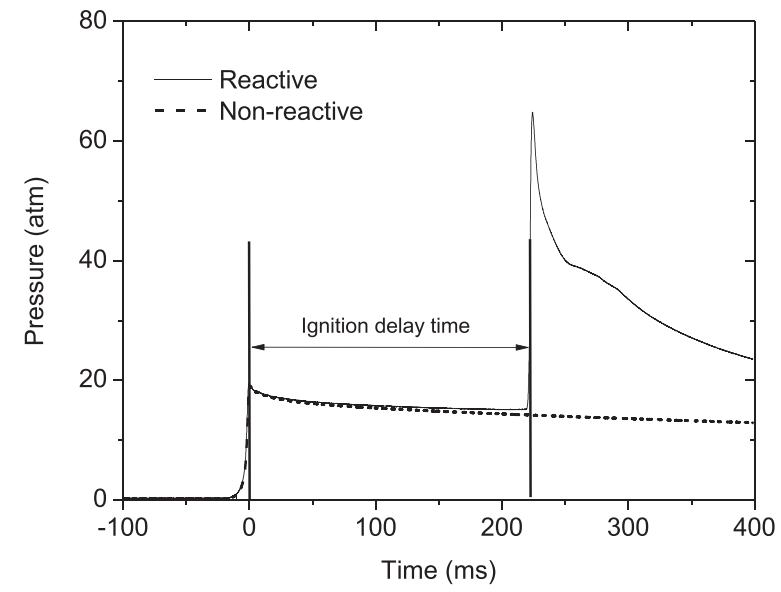

Fig. 3. Pressure trace with the definition of the ignition delay time in the rapid compression machine. Example for $\varphi=1, P=20$ atm (mixture 2C in Table 2), $T=795 \mathrm{~K}$.

Experimental uncertainty in ignition delay times was estimated as $\pm 15 \%$.

\subsection{Rapid compression machine}

Ignition delay times at low temperatures $(T=795-975 \mathrm{~K})$ and high pressures $(P=20$ and $40 \mathrm{~atm})$ (mixtures $1 \mathrm{C}-4 \mathrm{C}$ in Table 2) were measured in a rapid compression machine (RCM) described previously by Darcy et al. [31]. This machine has a twin opposedpiston configuration, resulting in a fast compression time of approximately $16 \mathrm{~ms}$. Creviced piston heads were used to suppress the in-cylinder roll-up vortices within the combustion chamber and thus to improve the post-compression temperature distribution in the chamber. Compressed gas temperatures were varied by adjusting the initial temperature of the reaction chamber surfaces (maximum temperature of $393 \mathrm{~K}$ ) via an electrical heating system around the reaction chamber. The compressed gas temperature, $T_{C}$, was calculated from the initial temperature, $T_{i}$, initial pressure, $P_{i}$, reactant composition, and the experimentally measured compressed gas pressure, $P_{C}$. For this calculation, the adiabatic compression/expansion routine in Gaseq [27], which uses the temperature dependence of the specific heat ratio of the test mixture, $\gamma$, according to the equation Eq. (1), was employed.

$\ln \left(\frac{p_{C}}{p_{i}}\right)=\int_{T_{i}}^{T_{C}} \frac{\gamma}{\gamma-1} \frac{d T}{T}$

The signal from a Kistler 603B piezoelectronic pressure transducer, installed in the combustion chamber, monitored the pressure during each experiment and was recorded using a digital oscilloscope. The ignition delay time was defined as the time interval from the end of compression (first local maximum on the pressure trace) to the maximum rate of pressure rise due to ignition (Fig. 3). An uncertainty of $\pm 15 \%$ is stimated for the RCM ignition delay time measurements.

Non-reactive experiments were carried out under the same conditions as the corresponding reactive case in order to obtain pressure-time histories which are converted to volume-time histories (using the isentropic relationship between pressure and density) to be used in the simulations of the reactive mixtures. In this way, facility effects including reaction during compression and heat loss are taken into account [32]. The non-reactive mixtures were prepared by substituting $\mathrm{O}_{2}$ in the reactive mixture for the diluent gas being used. Due to the unreactive behaviour of DMC, the diluent gas used in the RCM experiments was Ar, which has a lower heat capacity than $\mathrm{N}_{2}$. In this way, the specific heat ratio $\left(\gamma=C_{p} / C_{v}\right)$ of the test gas increases allowing to achieve higher compressed temperatures. Figure 3 presents a typical pressure trace measured in the RCM with the reactive and non-reactive mixture. As observed in Fig. 3, only pressure rise due to compression of the gas is detected during the non-reactive experiments.

\section{Modeling}

CHEMKIN-PRO [33] was used to simulate our measured ignition delay times. For the simulations in the shock tubes, constant volume conditions were assumed, while for the RCM variable volumetime histories were employed to include facility effects [32].

As mentioned in the introduction, heretofore three submechanisms have been proposed in the literature to describe DMC oxidation $[9,16,18]$. The first one was developed in 2005 by Glaude et al. [9]. This sub-mechanism was added to a base mechanism previously developed for DMM and DME $[10,11]$. The reaction rate constants for reactions involving DMC were obtained by analogies based on the reaction rate constants for other oxygenated compounds including dimethyl ether, formic acid, and methyl butanoate. The complete model (henceforth called the GlaudeDMC model) consists of 102 species and 442 reactions.

A decade later, Hu et al. [16] developed a new sub-mechanism for DMC oxidation which contains the same reaction classes as those contained in the sub-mechanism of Glaude et al. [9] (i.e. unimolecular decomposition, $\mathrm{H}$-atom abstraction, ether-acid conversion, $\mathrm{H}$-atom abstraction of $\mathrm{CH}_{3} \mathrm{O}(\mathrm{C}=\mathrm{O}) \mathrm{OH}$ formed from the etheracid conversion, and radical decomposition. There are a total of 24 elementary reactions). Most of the rate constants of these reactions are the same as in the DMC sub-mechanism of Glaude et al. [9], while other rate constants were modified to satisfactorily predict their ignition delay time measurements. In particular, the rate constants for the $\mathrm{CH}_{3} \mathrm{OC}(=\mathrm{O}) \mathrm{O}-\mathrm{CH}_{3}$ and $\mathrm{CH}_{3} \mathrm{OC}(=\mathrm{O})$ $\mathrm{OCH}_{3}$ bond cleavage reactions, producing $\mathrm{CH}_{3} \mathrm{O}(\mathrm{C}=\mathrm{O}) \dot{\mathrm{O}}+\dot{\mathrm{C}}_{3}$ and $\mathrm{CH}_{3} \mathrm{O} \dot{\mathrm{C}}=\mathrm{O}+\mathrm{CH}_{3} \dot{\mathrm{O}}$, respectively, were modified by those recommended by Dooley et al. [34] for the $\mathrm{C}_{3} \mathrm{H}_{7}-\mathrm{C}(=\mathrm{O}) \mathrm{O}-\mathrm{CH}_{3}$ and $\mathrm{C}_{3} \mathrm{H}_{7}-\mathrm{C}(=\mathrm{O})-\mathrm{OCH}_{3}$ bond cleavage reactions in methyl butanoate. Moreover, the rate constants of the $\mathrm{H}$-atom abstraction from DMC by $\mathrm{O}_{2}, \dot{\mathrm{H}}$ and $\mathrm{O}$ atoms, and $\dot{\mathrm{C}}_{2} \mathrm{H}_{3}, \dot{\mathrm{C}}_{2} \mathrm{H}_{5}, \dot{\mathrm{C}} \mathrm{H}_{3}, \mathrm{CH}_{3} \dot{\mathrm{O}}, \mathrm{CH}_{3} \dot{\mathrm{O}}_{2}, \mathrm{HO}_{2}$ radicals were assumed to be identical to those for methyl butanoate. As for the base mechanism, Hu used the AramcoMech 1.3 mechanism [17]. The complete model (henceforth called the HuDMC model) consists of 275 species and 1586 reactions.

One year later (2016), Sun et al. [18] developed a new submechanism for DMC conversion including new theoretical determinations and updated rates from literature and analogies. Comparing this most recent sub-mechanism with those of Glaude et al. [9] and $\mathrm{Hu}$ et al. [16], new reactions were added (e.g. the unimolecular decomposition reactions $\mathrm{CH}_{3} \mathrm{O}(\mathrm{C}=\mathrm{O}) \mathrm{OCH}_{3} \rightleftarrows$ $\mathrm{CH}_{3} \mathrm{OC} \mathrm{COO}+\mathrm{CH}_{2} \mathrm{O}$ and $\mathrm{CH}_{3} \mathrm{O}(\mathrm{C}=\mathrm{O}) \mathrm{OCH}_{3} \rightleftarrows \mathrm{CH}_{3} \mathrm{O}(\mathrm{C}=\mathrm{O}) \mathrm{OCH}+\mathrm{H}_{2}$; the hydrogen abstraction reaction $\mathrm{CH}_{3} \mathrm{O}(\mathrm{C}=\mathrm{O}) \mathrm{OCH}_{3}+\mathrm{HCO} \rightleftarrows$ $\mathrm{CH}_{3} \mathrm{O}(\mathrm{C}=\mathrm{O}) \mathrm{OCH}_{2}+\mathrm{CH}_{2} \mathrm{O}$; and additionally the recombination reaction of $\dot{\mathrm{CH}}_{3}$ and $\mathrm{CH}_{3} \mathrm{OC}(=\mathrm{O}) \mathrm{OC}_{2}$ radicals), while other reactions were omitted (those involved in the ether-acid conversion and $\mathrm{H}$-atom abstraction from $\left.\mathrm{CH}_{3} \mathrm{O}(\mathrm{C}=\mathrm{O}) \mathrm{OH}\right)$. In total, Sun's submechanism for the DMC conversion incorporates 23 elementary reactions. The AramcoMech 1.3 [17] was also used as the base mechanism. The complete model (henceforth called the SunDMC model) consists of 257 species and 1563 reactions.

Most recently, Alzueta et al. [19] developed a model by adding the DMC sub-mechanism from Glaude et al. [9] to a base mechanism described and updated by the authors [20-24]. The complete model (henceforth called the AlzuetaDMC model) consists of 284 species and 1206 reactions. Alzueta et al. [19], highlighted the importance of the thermodynamic data of the species involved in the DMC sub-mechanism describing DMC oxidation, specifically 
Table 3

Enthalpy of formation of DMC and its associated species used in the GlaudeDMC, HuDMC, SunDMC and AlzuetaDMC models.

\begin{tabular}{|c|c|c|c|}
\hline \multirow[b]{2}{*}{ Species } & \multicolumn{3}{|l|}{$H_{\mathrm{f} 298 \mathrm{~K}}^{\circ}(\mathrm{kcal} / \mathrm{mol})$} \\
\hline & $\begin{array}{l}\text { GlaudeDMC and HuDMC } \\
\text { (CBS-Q method) }\end{array}$ & $\begin{array}{l}\text { SunDMC (Group additivity method } \\
\text { using THERM [35] software) }\end{array}$ & $\begin{array}{l}\text { AlzuetaDMC (Group additivity method } \\
\text { using THERM [35] software) }\end{array}$ \\
\hline $\mathrm{CH}_{3} \mathrm{O}(\mathrm{C}=\mathrm{O}) \mathrm{OCH}_{3}$ & -136.06 & -135.85 & -136.05 \\
\hline $\mathrm{CH}_{3} \mathrm{O}(\mathrm{C}=\mathrm{O}) \mathrm{OC}^{-} \mathrm{H}_{2}$ & -88.10 & -86.843 & -91.59 \\
\hline $\mathrm{CH}_{3} \mathrm{O}(\mathrm{C}=\mathrm{O}) \mathrm{OH}$ & -140.93 & - & -141.77 \\
\hline $\mathrm{CH}_{3} \mathrm{O}(\mathrm{C}=0) \mathrm{O}$ & -82.29 & -83.85 & -89.90 \\
\hline $\mathrm{C}_{2} \mathrm{O}(\mathrm{C}=\mathrm{O}) \mathrm{OH}$ & -93.64 & - & -97.39 \\
\hline
\end{tabular}

Table 4

Rate coefficients in form of $\mathrm{k}=\mathrm{AT} \exp \left(-\mathrm{E} / \mathrm{RT}\right.$ ) for reaction $\mathrm{CH}_{3} \mathrm{O}(\mathrm{C}=\mathrm{O}) \mathrm{OCH}_{3} \rightleftarrows \mathrm{CH}_{3} \mathrm{O}(\mathrm{C}=\mathrm{O}) \mathrm{O}+\mathrm{CH}_{3}$ (units: $\mathrm{cm}^{3} / \mathrm{mol} / \mathrm{s} / \mathrm{cal}$ ) in the $\mathrm{GlaudeDMC}$, $\mathrm{HuDMC}$, SunDMC and AlzuetaDMC models.

\begin{tabular}{|c|c|c|c|c|c|}
\hline Model & Reaction & & $A$ & $\rightarrow$ & E \\
\hline GlaudeDMC AlzuetaDMC & $\mathrm{CH}_{3} \mathrm{O}(\mathrm{C}=\mathrm{O}) \dot{\mathrm{O}}+\dot{\mathrm{C}}_{3} \rightleftarrows \mathrm{CH}_{3} \mathrm{O}(\mathrm{C}=\mathrm{O}) \mathrm{OCH}_{3}{ }^{\mathrm{a}}$ & & $3.00 \times 10^{13}$ & 0.00 & 0.00 \\
\hline $\mathrm{HuDMC}^{\mathrm{b}}$ & $\mathrm{CH}_{3} \mathrm{O}(\mathrm{C}=\mathrm{O}) \mathrm{OCH}_{3}(+\mathrm{M}) \rightleftarrows \mathrm{CH}_{3} \mathrm{O}(\mathrm{C}=\mathrm{O}) \dot{\mathrm{O}}+\dot{\mathrm{C}} \mathrm{H}_{3}(+\mathrm{M})^{\mathrm{b}}$ & & $\begin{array}{l}2.55 \times 10^{23} \\
\text { low } / 1.74 \times 10^{73} \\
\text { troe } / 2.18 \times 10^{-1}\end{array}$ & $\begin{array}{l}-1.99 \\
-1.60 \times 10^{1} \\
1.06 .37 \times 10^{3}\end{array}$ & $\begin{array}{l}8.81 \times 10^{4} \\
8.53 \times 10^{4} / \\
8.21 \times 10^{9}\end{array}$ \\
\hline SunDMC & $\mathrm{CH}_{3} \mathrm{O}(\mathrm{C}=\mathrm{O}) \mathrm{OCH}_{3} \rightleftarrows \mathrm{CH}_{3} \mathrm{O}(\mathrm{C}=\mathrm{O}) \dot{\mathrm{O}}+\dot{\mathrm{CH}}_{3}{ }^{\mathrm{c}}$ & $\begin{array}{l}\text { plog/ } 0.04 \\
\text { plog / } 0.1 \\
\text { plog / } 0.5 \\
\text { plog / 1 } \\
\text { plog / } 10 \\
\text { plog / } 100 \\
\text { plog / } 1000\end{array}$ & $\begin{array}{l}2.86 \times 10^{75} \\
7.95 \times 10^{72} \\
1.13 \times 10^{67} \\
1.29 \times 10^{64} \\
9.42 \times 10^{59} \\
3.51 \times 10^{52} \\
8.70 \times 10^{26}\end{array}$ & $\begin{array}{l}-17.58 \\
-16.71 \\
-14.82 \\
-13.89 \\
-12.43 \\
-10.08 \\
-3.51\end{array}$ & $\begin{array}{l}112,569 . \\
112,126 \\
110,484 \\
109,488 \\
110,018 \\
108,107 \\
79,326\end{array}$ \\
\hline
\end{tabular}

\footnotetext{
a Assumed the same rate as high pressure rate for $\mathrm{CH}_{3} \dot{\mathrm{O}}+\dot{\mathrm{C}} \mathrm{H}_{3} \rightarrow \mathrm{CH}_{3} \mathrm{OCH}_{3}$ [10].

b Adopted from the decomposition of methyl butanoate in the work of Dooley et al. [34].

c Calculated using the master equation code-PAPER [36].
}

the thermodynamic data of the $\mathrm{CH}_{3} \mathrm{O}(\mathrm{C}=\mathrm{O}) \mathrm{O}$ radical species. The enthalpy of formation of DMC and its associated species in each model, with the corresponding methods for their calculations, are provided in Table 3.

The performance of all four models in predicting the ignition delay times of this work, as well as the influence of the thermodynamic data of the $\mathrm{CH}_{3} \mathrm{O}(\mathrm{C}=\mathrm{O}) \mathrm{O}$ radical species on the ignition delay time calculated by each model will be discussed in the following section.

\section{Results and discussion}

This section is divided into three parts. The first part shows the performance of the four aforementioned models (GlaudeDMC, HuDMC, SunDMC, and AlzuetaDMC) in simulating the experimental ignition delay times of this work. The second investigates the influence of the thermodynamic of the $\mathrm{CH}_{3} \mathrm{O}(\mathrm{C}=\mathrm{O}) \mathrm{O}$ radical species on the calculations of the ignition delay times for all four models, by changing the thermodynamic of this radical in each model by the thermodynamic of this radical in the other models. The third provides a chemical interpretation of the effect of the DMC concentration, pressure and equivalence ratio on the ignition delay times for DMC oxidation by performing rate of production (ROP) and sensitivity analyses.

\subsection{Performance of the models}

Examples of the performance of the GlaudeDMC, HuDMC, SunDMC and AlzuetaDMC models to predict the measured ignition delay times at low (1.75\% DMC, $\varphi=1, P=2$ atm, mixture $5 \mathrm{~A}$ in Table 1$)$ and high $(\varphi=1, P=20$ atm, mixtures $2 \mathrm{~B}$ and $2 \mathrm{C}$ in Table 2 ) pressure are provided in Fig. 4.

It can be seen that at low pressure (1.75\% DMC, $\varphi=1, P=2$ atm, Fig. 4a) the GlaudeDMC model significantly overpredicts the experimental ignition delay times over the entire temperature range studied, while the HuDMC, SunDMC and AlzuetaDMC models underpredict them. Regarding the modeling at high pressure $(\varphi=1$,
$P=20$ atm, Fig. 4b), the GlaudeDMC and AlzuetaDMC models show the poorest predictions, especially at low temperatures $(\leq 870 \mathrm{~K})$. On the other hand, the HuDMC model agrees with the ignition delay times at high temperatures $(\geq 900 \mathrm{~K})$, while it shows a large underprediction of the ignition delay times at low temperatures $(\leq 870 \mathrm{~K})$. The SunDMC model predicts the ignition delay times over the entire temperature range studied moderately well, with only a slight under-prediction at the highest temperatures studied $(\geq 1250 \mathrm{~K})$. The same behavior in predictions is observed for all the remaining experimental data at low and high pressure (not shown).

Overall, the SunDMC model best predicts the measured data at high pressure over the entire temperature range studied. However, the good prediction at high pressure but not at low pressure (large underprediction) indicates that this model shows a weaker pressure dependence compared to that observed in the experiments. This could be attributed principally to the uncertainty in the rate coefficients of the unimolecular decomposition reactions of the fuel in the SunDMC model.

\subsection{Effect of the thermodynamic of the $\mathrm{CH}_{3} \mathrm{O}(\mathrm{C}=\mathrm{O}) \dot{\mathrm{O}}$ radical species} on the simulations

As discussed earlier/above, Alzueta et al. [19] found that the thermodynamic data of the $\mathrm{CH}_{3} \mathrm{O}(\mathrm{C}=\mathrm{O}) \mathrm{O}$ radical species greatly influences their calculations of DMC oxidation. Thus, to observe this influence on the calculation of the ignition delay time data of the present work, the thermodynamics of this radical was changed in each of the four models (GlaudeDMC, HuDMC, SunDMC, and AlzuetaDMC) and simulations were run. This change in thermodynamics only represented an effect on the simulation data using the GlaudeDMC and AlzuetaDMC models (Figs. 5 and 6, respectively) throughout the temperature range studied at low pressure, and at high temperatures $(\geq 950 \mathrm{~K})$ at high pressure, while the simulation data at high pressure and low temperatures $(\leq 870 \mathrm{~K})$ was not affected. 

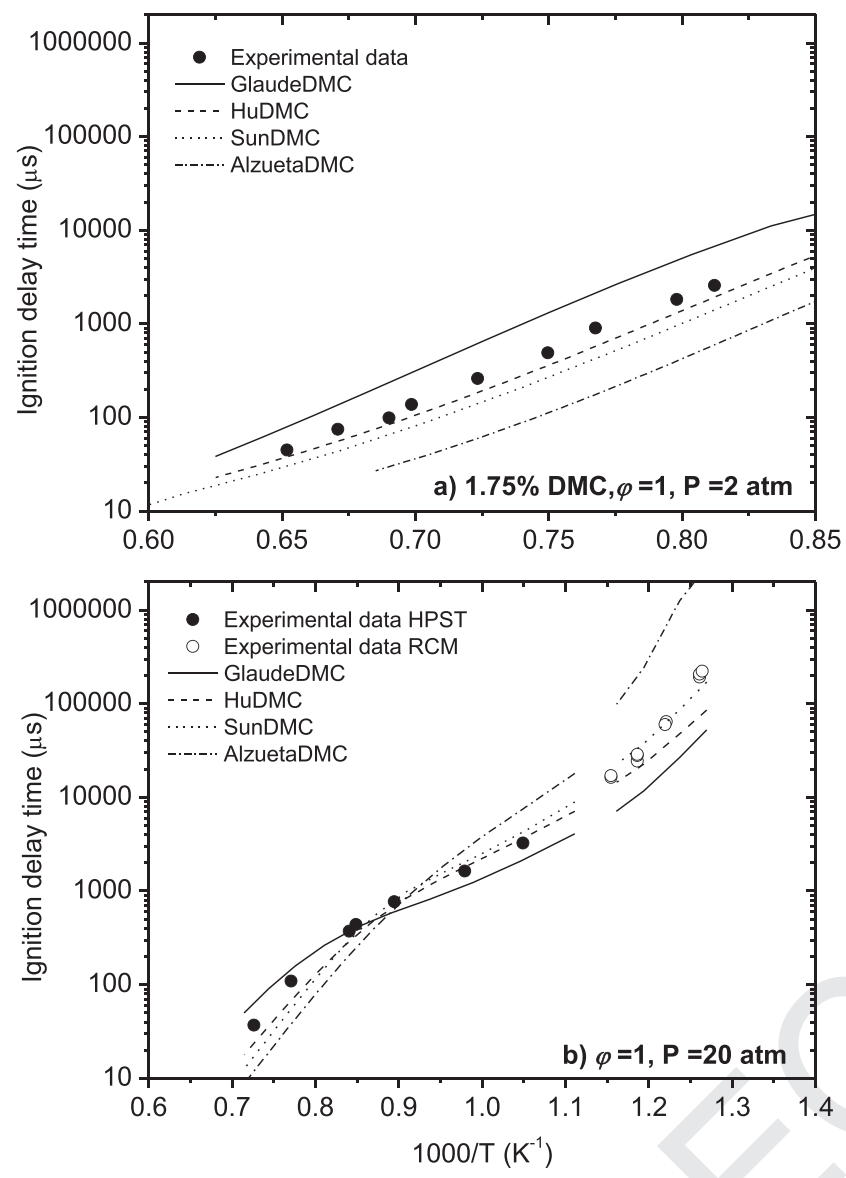

Fig. 4. Measured (symbols) ignition delay times in conjunction with calculations (lines) using GlaudeDMC, HuDMC, SunDMC and AlzuetaDMC models. a) 1.75\% DMC $\varphi=1, P=2 \mathrm{~atm}$ (mixture $5 \mathrm{~A}$ in Table 1 ), and b) $\varphi=1, P=20$ atm (mixtures $2 \mathrm{~B}$ and $2 \mathrm{C}$ in Table 2).

The unimolecular $\mathrm{DMC}$ decomposition reaction $\mathrm{CH}_{3} \mathrm{O}(\mathrm{C}=\mathrm{O}) \mathrm{OCH}_{3} \rightleftarrows \mathrm{CH}_{3} \mathrm{O}(\mathrm{C}=\mathrm{O}) \dot{\mathrm{O}}+\mathrm{CH}_{3}$ (R1), reported to be important for the fuel consumption at high temperatures $[13,16,18]$, and which rate constant is the same in both GlaudeDMC and AlzuetaDMC models (Table 4), was identified to be the cause of this event. When this reaction in GlaudeDMC and AlzuetaDMC models was replaced by that in the HuDMC and SunDMC models, the thermodynamics of the $\mathrm{CH}_{3} \mathrm{O}(\mathrm{C}=\mathrm{O}) \mathrm{O}$ radical species had no any effect on the simulation data, as can be seen in Figs. 7 and 8, respectively.

Moreover, when reaction R1 in HuDMC and SunDMC models was replaced by that in the GlaudeDMC/AlzuetaDMC model, the thermodynamics of the $\mathrm{CH}_{3} \mathrm{O}(\mathrm{C}=\mathrm{O}) \mathrm{O}$ radical species influenced the calculations by these two models (Figs. 9 and 10). As in Figs. 7 and 8 , this influence occurs all over the temperature range studied at low pressure, while at high pressure, there is not effect of the thermodynamic of the $\mathrm{CH}_{3} \mathrm{O}(\mathrm{C}=\mathrm{O}) \mathrm{O}$ radical species on the calculations at low temperature, which indicates that reaction $\mathrm{R} 1$ does not control the prediction of ignition delay times at low temperatures. Also note that calculations with the HuDMC model using the reaction R1 in the SunDMC model (Fig. 9), and vice versa (Fig. 10), were not affected when the thermodynamics of the $\mathrm{CH}_{3} \mathrm{O}(\mathrm{C}=\mathrm{O}) \dot{\mathrm{O}}$ radical species was changed.

Figures 4-10 show that simulations with the SunDMC model that incorporate reaction R1 from the HuDMC model (Fig. 10) (modified SunDMC model, henceforth called SunDMC_mod) agree better with the experimental data at $1.75 \%$ DMC, $\varphi=1, P=2$ atm
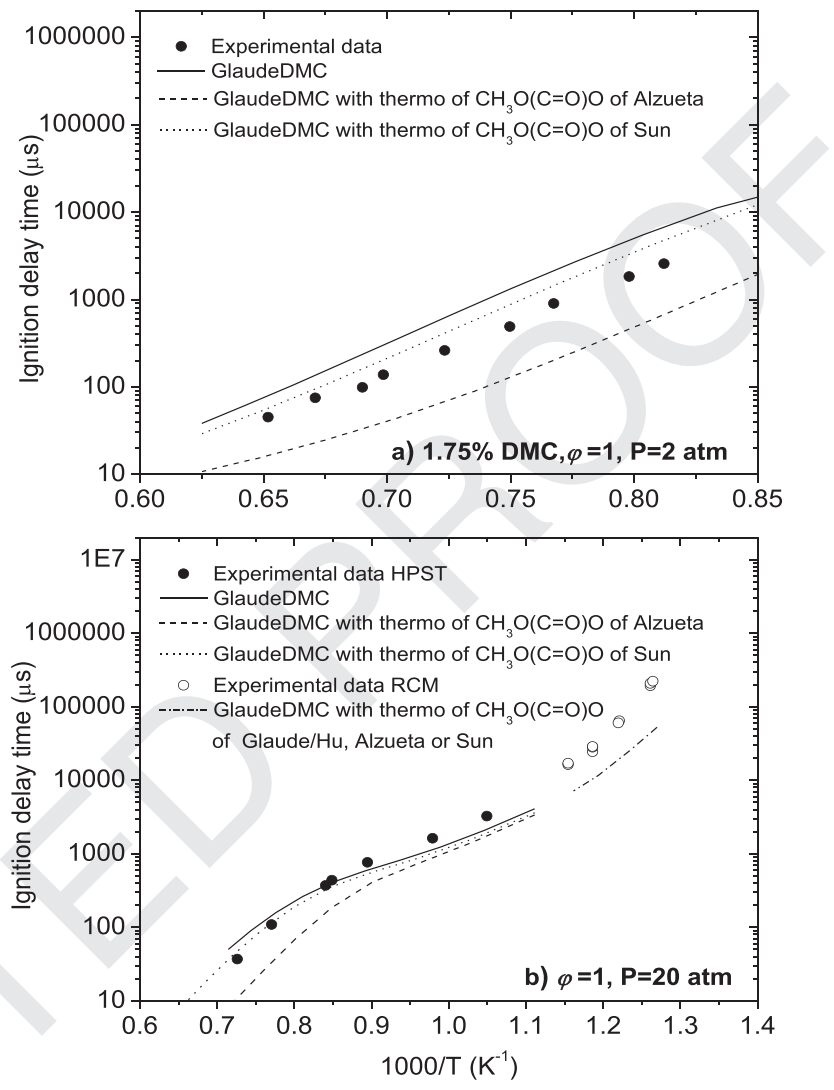

Fig. 5. Effect of the thermodynamic of the $\mathrm{CH}_{3} \mathrm{O}(\mathrm{C}=\mathrm{O}) \dot{\mathrm{O}}$ radical species on the calculations of the ignition delay time by the GlaudeDMC model. a) $1.75 \%$ DMC, $\varphi=1$, $P=2 \mathrm{~atm}$ (mixture $5 \mathrm{~A}$ in Table 1 ), and $\mathrm{b}) \varphi=1, P=20 \mathrm{~atm}$ (mixtures $2 \mathrm{~B}$ and $2 \mathrm{C}$ in Table 2).

(Fig. 10a), and $\varphi=1, P=20$ atm (Fig. 10b), than the original (Fig. 4) 412 and the modified (Figs. 5-9) models.

Besides reaction $\mathrm{R} 1$, the reaction $\mathrm{CH}_{3} \mathrm{O}(\mathrm{C}=\mathrm{O}) \mathrm{OCH}_{3} \rightleftarrows 414$ $\mathrm{CH}_{3} \mathrm{OCH}_{3}+\mathrm{CO}_{2}$ (R2) has been reported $[13,18]$ to be a domi- 415 nant decomposition channel, and thus competes with reaction 416 $\mathrm{R} 1$. Thereby, the ignition is also influenced by the $k_{1} /\left(k_{1}+k_{2}\right) \quad 417$ branching ratio. The rate constant, $k_{1}$ in $\mathrm{Hu}$ et al. [16] was 418 adopted from the decomposition of methyl butanoate in the work 419 of Dooley et al. [34], and is in reasonable agreement with the 420 reaction rate measured directly by Peukert et al. [13]. On the 421 other hand, $k_{2}$ used by Sun et al. [18] was determined by master 422 equation analysis and is also in agreement with that measured by 423 Peukert et al. [13], being improved in relation to that used by $\mathrm{Hu} 424$ et al. [16] which was taken from the estimation of Glaude et al. 425 [9] based on reactivity analogy.

Calculations for the remaining experimental conditions studied (1.75\% DMC: $\varphi=0.5$ and 2.0; 0.75\% DMC: $\varphi=0.5,1.0$ and 2.0; $P=20$ atm: $\varphi=0.5$ and $2.0 ; P=40$ atm: $\varphi=0.5,1.0$ and 2.0) were performed using the SunDMC_mod model. This model predicts our measured ignition delay times at both low and high pressures and at all of the temperatures and equivalence ratios studied. As mentioned earlier, the SunDMC_mod model uses AramcoMech 1.3 as the base mechanism, and replacing this with AramcoMech 2.0 [37], i.e., the sub-mechanism for the DMC conversion in the SunDMC_mod model has been added to the AramcoMech 2.0 mechanism (this final model will be called AramcoMech2.0 + SunDMC_mod), had no effect on our ignition delay time predictions. The thermodynamic data used correspond to the same sources as the reactions, i.e., all the thermodynamic data are from AramcoMech 2.0 except the thermodynamics of DMC and its 14 15 16 17 8 0 21 22 24 

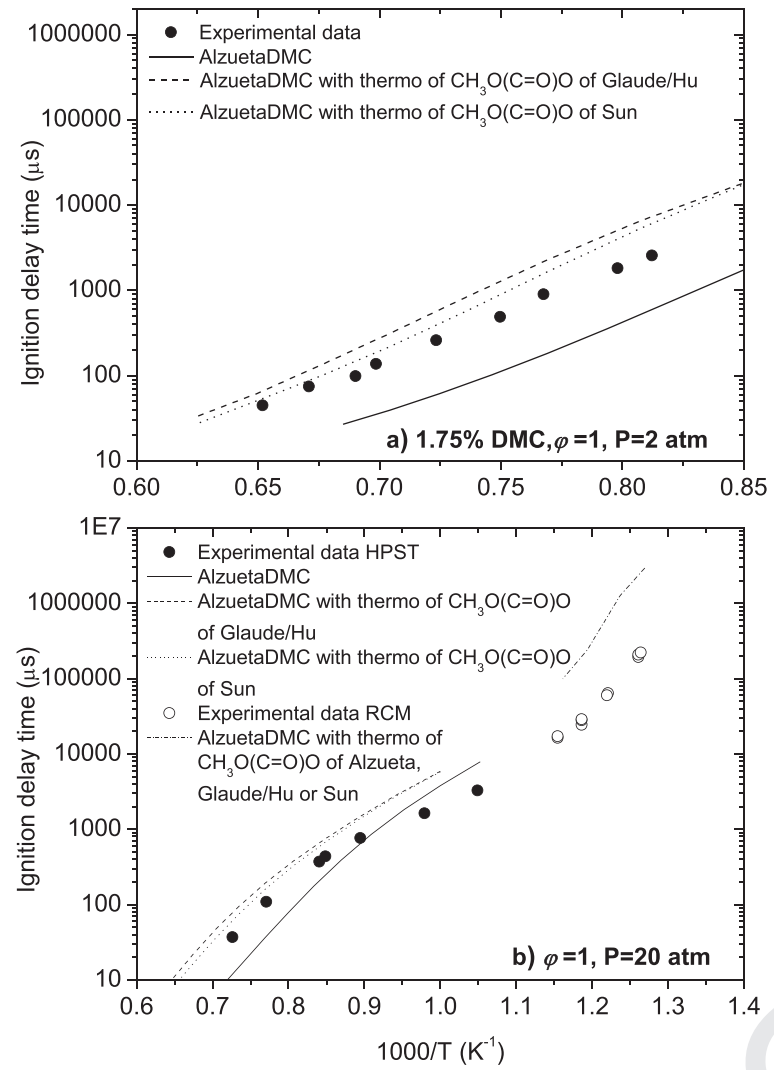

Fig. 6. Effect of the thermodynamic of the $\mathrm{CH}_{3} \mathrm{O}(\mathrm{C}=0) \mathrm{O}$ radical species on the calculations of the ignition delay time by the AlzuetaDMC model. a) $1.75 \%$ DMC, $\varphi=1$, $P=2 \mathrm{~atm}$ (mixture $5 \mathrm{~A}$ in Table 1 ), and $\mathrm{b}) \varphi=1, P=2$ atm (mixtures $2 \mathrm{~B}$ and $2 \mathrm{C}$ in Table 2).
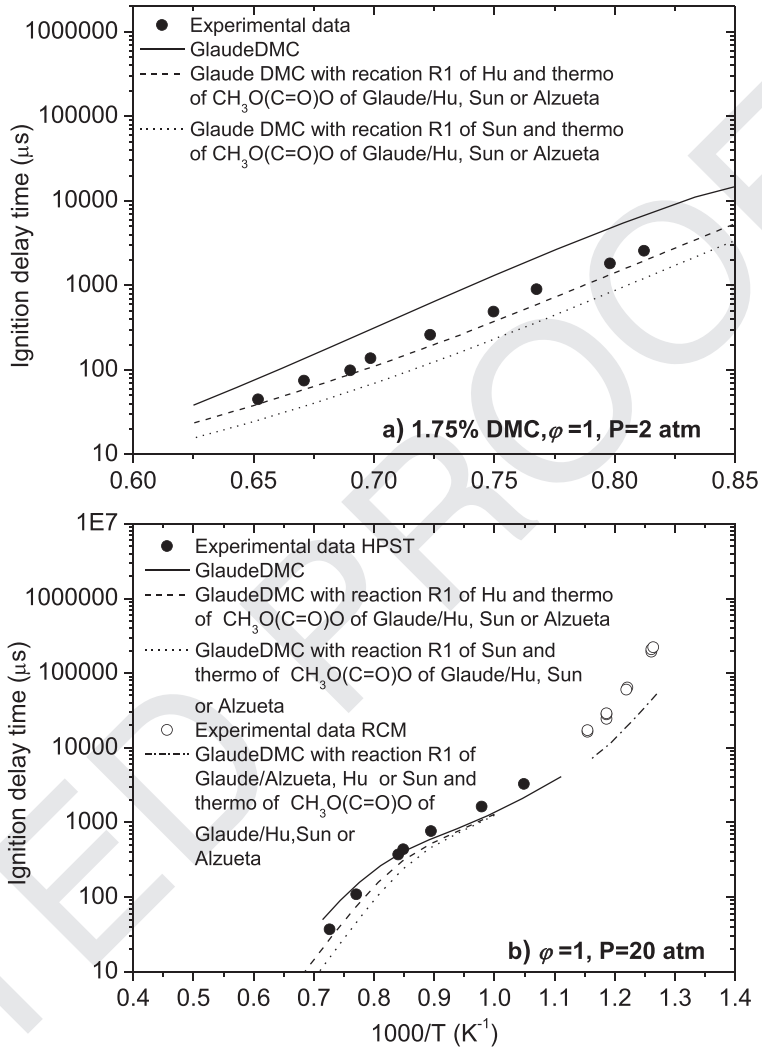

Fig. 7. Effect of reaction $\mathrm{R} 1$ on the calculations of the ignition delay time by the GlaudeDMC model, and effect of the thermodynamic of the $\mathrm{CH}_{3} \mathrm{O}(\mathrm{C}=\mathrm{O}) \dot{\mathrm{O}}$ radical species with the change of reaction R1. a) $1.75 \%$ DMC, $\varphi=1, P=2$ atm (mixture $5 \mathrm{~A}$ in Table 1 ), and b) $\varphi=1, P=20$ atm (mixtures $2 \mathrm{~B}$ and $2 \mathrm{C}$ in Table 2 ). where $\tau_{k \times 2}$ is the simulated ignition delay time when a rate constant is increased by a factor of 2 and $\tau_{k / 2}$ is that predicted when a rate constant is decreased by a factor of 2 . Therefore, a negative sensitivity coefficient denotes a rate constant that promotes reactivity (decreasing ignition delay time by increasing the rate constant), and vice versa.

The reaction pathway analysis depicted in Fig. 12, which was carried out at the time of 20\% DMC conversion, indicates that the major paths associated with DMC consumption are two DMC unimolecular decompositions reactions and the $\mathrm{H}$-atom abstraction from DMC, principally by $\dot{\mathrm{H}}$ atoms and $\dot{\mathrm{OH}}$ radicals.

The most important pathway for DMC consumption is its unimolecular decomposition to produce dimethyl ether $\left(\mathrm{CH}_{3} \mathrm{OCH}_{3}\right)$ and $\mathrm{CO}_{2}$ (reaction $\mathrm{R} 2$ ). $35 \%$ and $32.4 \%$ of the fuel decomposes by this route for the $0.75 \%$ and $1.75 \%$ DMC mixtures, respectively.

The $\mathrm{CH}_{3} \mathrm{OCH}_{3}$ so formed can be largely consumed via two main pathways: (a) $\mathrm{H}$-atom abstraction by $\dot{\mathrm{H}}$ atoms (31.1\%, 25.8\%), and $\dot{\mathrm{OH}}(25.2 \%, 30.6 \%)$ and $\dot{\mathrm{C}} \mathrm{H}_{3}(15.9 \%, 19.2 \%)$ radicals (with percentages in brackets corresponding to mixture of $0.75 \%$ and $1.75 \%$ DMC, respectively) to lead, in a further step, to the formation of formaldehyde and methyl radicals; or (b) decomposition to give $\dot{\mathrm{C}} \mathrm{H}_{3}$ and methoxy $\left(\mathrm{CH}_{3} \mathrm{O}\right)$ radicals $(23.4 \%, 19.7 \%)$ (reaction R3) which then principally decompose via reaction $\mathrm{R} 4$ to give formaldehyde and $\dot{\mathrm{H}}$ atoms (93.6 \%, 86.5\%).

$\mathrm{CH}_{3} \mathrm{OCH}_{3}(+\mathrm{M}) \rightleftarrows \dot{\mathrm{C}} \mathrm{H}_{3}+\mathrm{CH}_{3} \mathrm{O}(+\mathrm{M})$

$\mathrm{CH}_{3} \mathrm{O}(+\mathrm{M}) \rightleftarrows \mathrm{CH}_{2} \mathrm{O}+\dot{\mathrm{H}}(+\mathrm{M})$

The other important unimolecular decomposition reaction for 493 DMC consumption (although, based on our reaction pathway 494 analysis, it is the less important route) is reaction R1, which 495 expressed according to Eq. (2).

$S_{i}=\frac{\log _{10}\left(\tau_{k \times 2} / \tau_{k / 2}\right)}{\log _{10}(2 / 0.5)}$ 

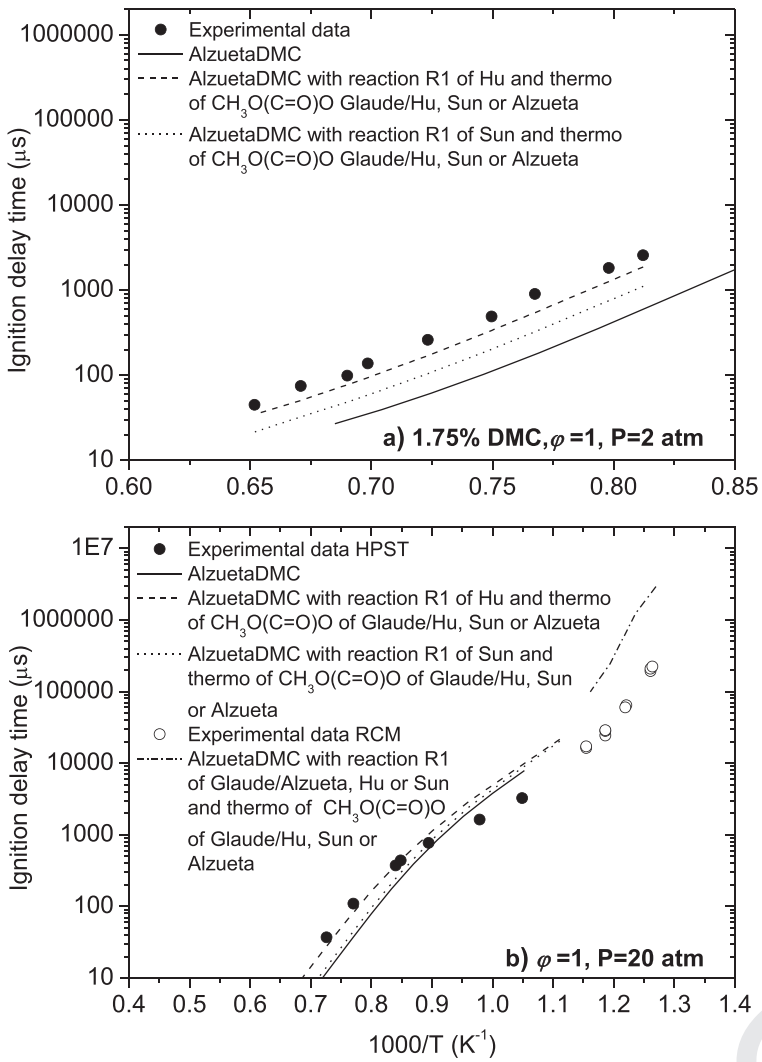

Fig. 8. Effect of reaction $\mathrm{R} 1$ on the calculations of the ignition delay time by the AlzuetaDMC model, and effect of the thermodynamic of the $\mathrm{CH}_{3} \mathrm{O}(\mathrm{C}=\mathrm{O}) \mathrm{O}$ radical species with the change of reaction R1. a) $1.75 \%$ DMC, $\varphi=1, P=2$ atm (mixture $5 \mathrm{~A}$ in Table 1), and b) $\varphi=1, P=20$ atm (mixtures $2 \mathrm{~B}$ and $2 \mathrm{C}$ in Table 2 ).

$\mathrm{CH}_{3} \mathrm{O}(\mathrm{C}=\mathrm{O}) \mathrm{OC} \mathrm{H}_{2} \rightleftarrows \mathrm{CH}_{3} \mathrm{OC}=\mathrm{O}+\mathrm{CH}_{2} \mathrm{O}$

$\mathrm{CH}_{3} \mathrm{O} \dot{\mathrm{C}}=\mathrm{O} \rightleftarrows \dot{\mathrm{C}} \mathrm{H}_{3}+\mathrm{CO}_{2}$

consumes $23.2 \%$ and $21.9 \%$ of the fuel for the mixtures with $0.75 \%$ and $1.75 \%$ DMC, respectively. The $\mathrm{CH}_{3} \mathrm{O}(\mathrm{C}=0) \dot{\mathrm{O}}$ radical formed totally decomposes to $\mathrm{CO}_{2}$ and $\mathrm{CH}_{3} \mathrm{O}$ radicals which mainly decomposes to formaldehyde and $\dot{\mathrm{H}}$ atoms via reaction $\mathrm{R} 4$.

$\mathrm{H}$-atom abstraction from DMC, principally by $\dot{\mathrm{H}}$ atoms $(24.4 \%$, $22.7 \%)$, to produce DMC radicals $\left(\mathrm{CH}_{3} \mathrm{O}(\mathrm{C}=0) \mathrm{OCH}_{2}\right)$ and molecular hydrogen (reaction R5), is the second-most important reaction for $\mathrm{CH}_{3} \mathrm{O}(\mathrm{C}=\mathrm{O}) \mathrm{OCH}_{3}+\dot{\mathrm{H}} \rightleftarrows \mathrm{CH}_{3} \mathrm{O}(\mathrm{C}=\mathrm{O}) \mathrm{OC}_{2}+\mathrm{H}_{2}$

The $\mathrm{CH}_{3} \mathrm{O}(\mathrm{C}=\mathrm{O}) \mathrm{OC}_{2}$ radicals formed can decompose to formaldehyde and methoxy formyl radicals $\left(\mathrm{CH}_{3} \mathrm{O} \dot{\mathrm{C}}=\mathrm{O}\right)$ (reaction R6), which in turns decompose to $\mathrm{CH}_{3}$ radicals and $\mathrm{CO}_{2}$ (reaction R7).

The sensitivity analysis provided in Fig. 13 indicates that the most important reactions promoting reactivity are the $\dot{\mathrm{H}}+\mathrm{O}_{2} \rightleftarrows$ $\ddot{\mathrm{O}}+\dot{\mathrm{O} H}$ (R8) chain-branching reaction and the fuel-specific reaction R1. However, the chain-branching reaction becomes less sensitive with increasing fuel concentration, while the specific-fuel reaction becomes more sensitive with increasing fuel concentration. The high dependence of the $1.75 \%$ DMC mixture on reaction R1 can explain the decrease in ignition delay times with increasing fuel concentration, since the higher the DMC concentration, the higher the reaction rate of reaction R1 leading to shorter (faster) ignition delay times.
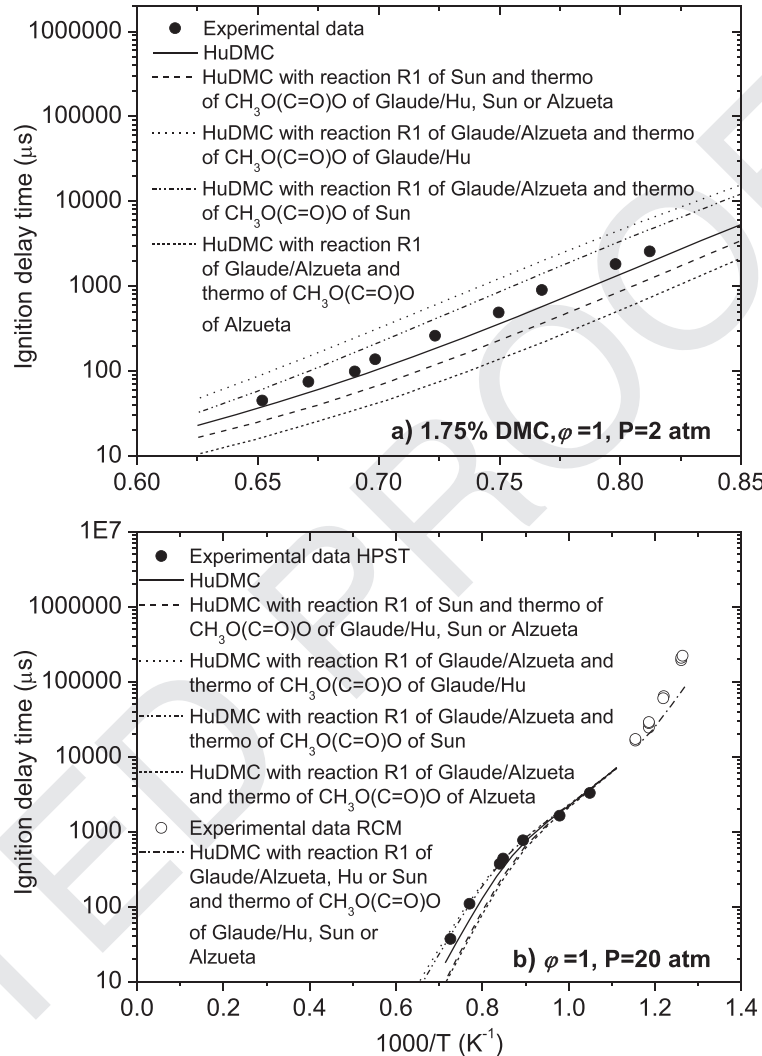

Fig. 9. Effect of reaction R1 on the calculations of the ignition delay time by the HuDMC model, and effect of the thermodynamic of the $\mathrm{CH}_{3} \mathrm{O}(\mathrm{C}=\mathrm{O}) \dot{\mathrm{O}}$ radical species with the change of reaction R1. a) $1.75 \%$ DMC, $\varphi=1, P=2$ atm (mixture $5 \mathrm{~A}$ in Table 1 ), and b) $\varphi=1, P=20 \mathrm{~atm}$ (mixtures $2 \mathrm{~B}$ and $2 \mathrm{C}$ in Table 2).
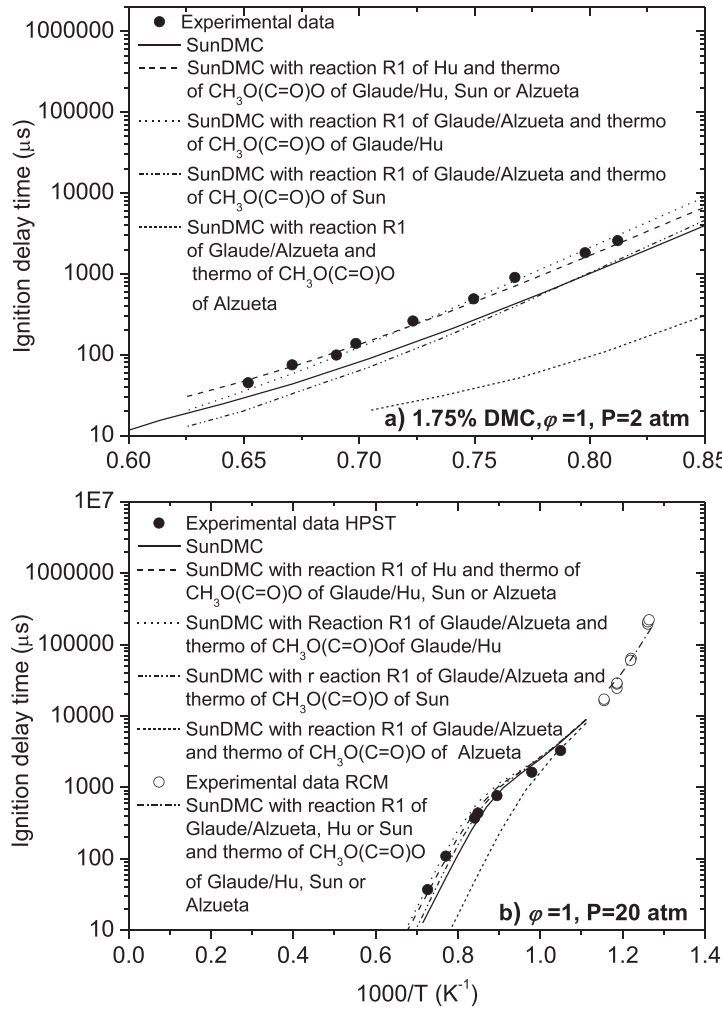

Fig. 10. Effect of reaction $\mathrm{R} 1$ on the calculations of the ignition delay time by the SunDMC model, and effect of the thermodynamic of the $\mathrm{CH}_{3} \mathrm{O}(\mathrm{C}=\mathrm{O}) \mathrm{O}$ radical species with the change of reaction R1. a) $1.75 \% \mathrm{DMC}, \varphi=1, P=2$ atm (mixture $5 \mathrm{~A}$ in Table 1), and b) $\varphi=1, P=20 \mathrm{~atm}$ (mixtures $2 \mathrm{~B}$ and $2 \mathrm{C}$ in Table 2). 

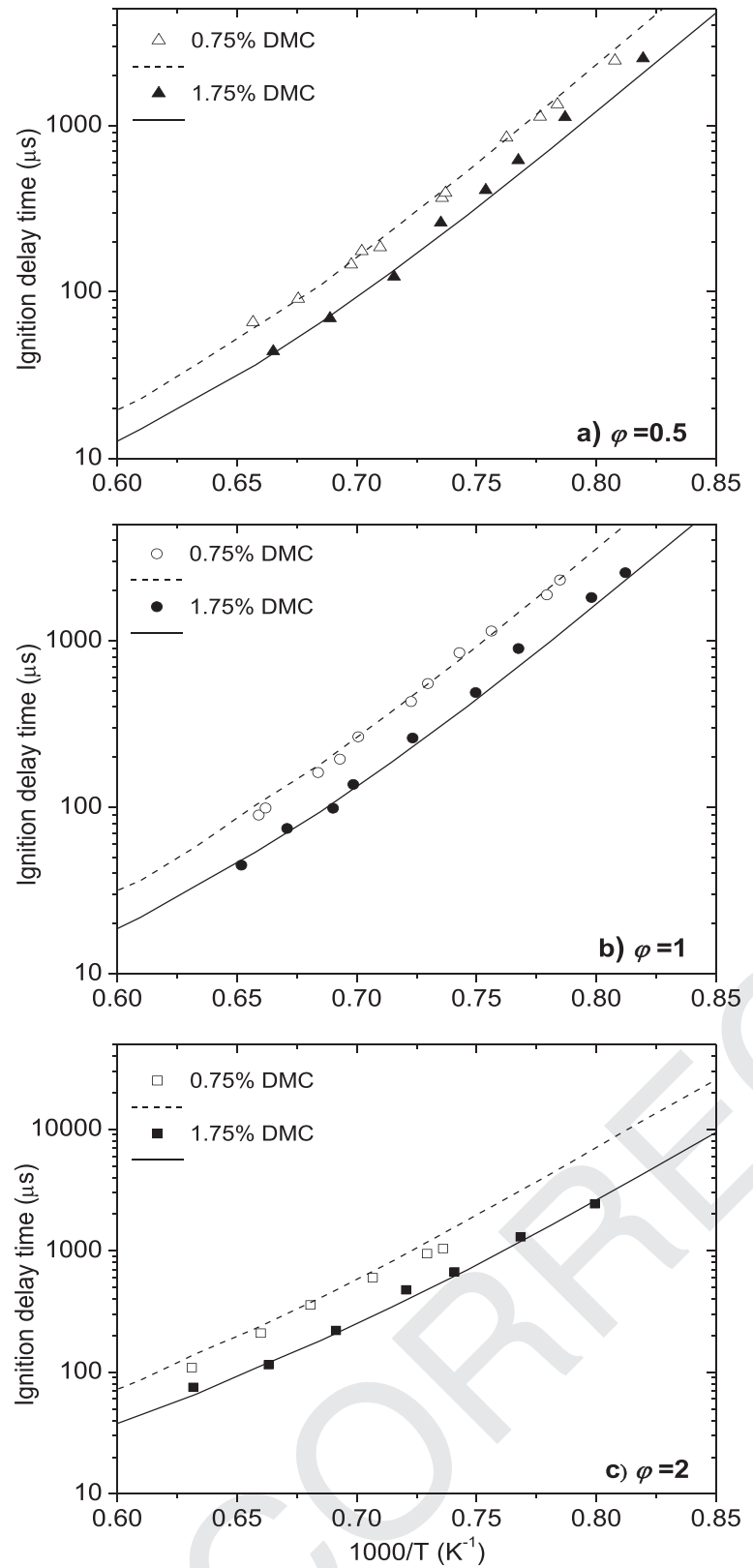

Fig. 11. Effect of DMC concentration on ignition delay times at $P=2$ atm and $\varphi=0.5$ (mixtures $1 \mathrm{~A}$ and $4 \mathrm{~A}$ in Table 1 ), 1.0 (mixtures $2 \mathrm{~A}$ and $5 \mathrm{~A}$ in Table 1 ), and 2.0 (mixtures $3 \mathrm{~A}$ and $6 \mathrm{~A}$ in table 1 ). Symbols: experimental data. Lines: AramcoMech2.0+SunDMC_mod modeling.

Reaction R1 leads to the formation of $\dot{\mathrm{C}} \mathrm{H}_{3}$ radicals, which promote reactivity, mainly for the $1.75 \%$ DMC mixture, due to reactions R9 and R10.

$\dot{\mathrm{C}} \mathrm{H}_{3}+\mathrm{HO}_{2} \rightleftarrows \mathrm{CH}_{3} \dot{\mathrm{O}}+\dot{\mathrm{O}} \mathrm{H}$

$\mathrm{CH}_{2} \mathrm{O}+\dot{\mathrm{C}} \mathrm{H}_{3} \rightleftarrows \mathrm{HC} \mathrm{O}+\mathrm{CH}_{4}$

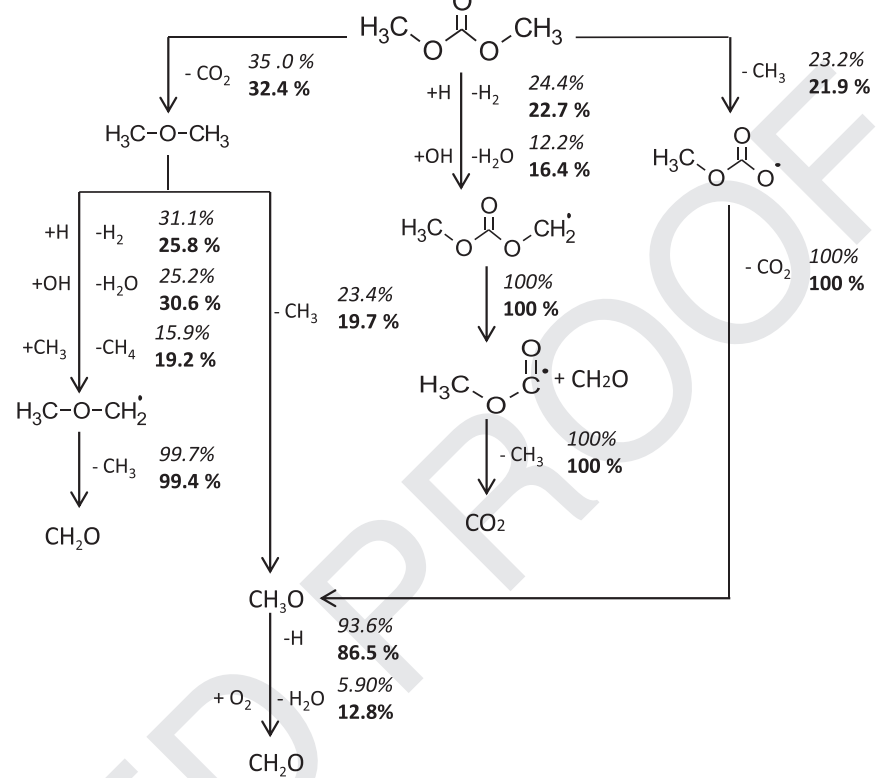

Fig. 12. Reaction pathway analysis for $0.75 \%$ DMC (italic font) and $1.75 \%$ DMC (bold font), $\varphi=1.0, P=2 \mathrm{~atm}, T=1350 \mathrm{~K}$. Carried out at the time of $20 \%$ fuel conversion.

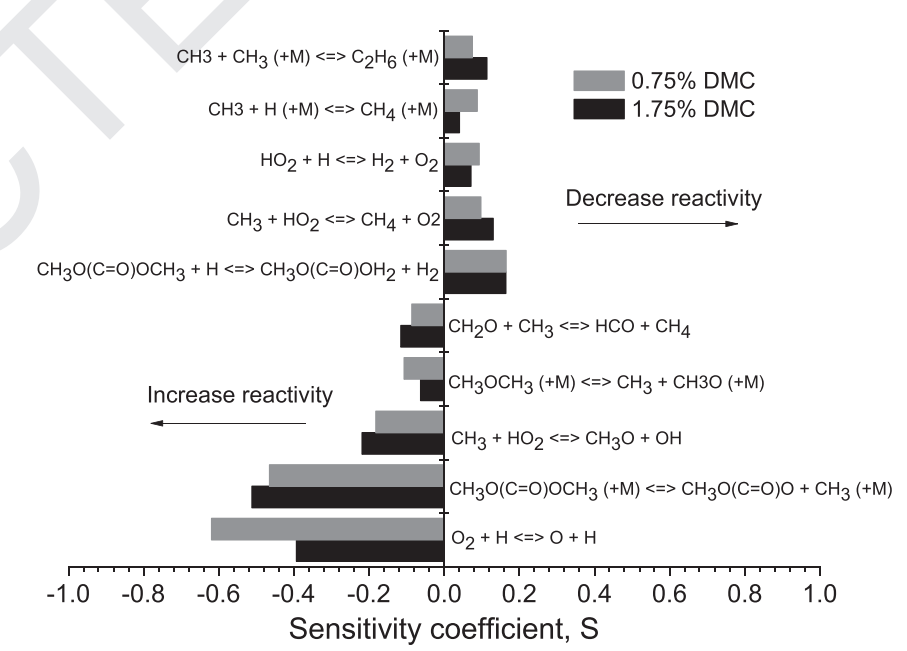

Fig. 13. Sensitivity analysis for $0.75 \%$ DMC and $1.75 \%$ DMC, $\varphi=1.0, P=2$ atm, $T=1350 \mathrm{~K}$.

Other important promoting reaction, mainly for the mixture 526 with $0.75 \%$ DMC, is the dimethyl ether decomposition reaction R3. 527 This reaction promotes reactivity because besides forming $\dot{\mathrm{C}} \mathrm{H}_{3}$ rad- 528 icals, it also produces reactive $\dot{H}$ atoms via the decomposition of 529 $\mathrm{CH}_{3} \mathrm{O}$ radicals (reaction $\mathrm{R} 4$ ).

$\mathrm{H}$-atom abstraction from DMC by $\dot{\mathrm{H}}$ atoms (reaction $\mathrm{R} 5$ ), is the most inhibiting reaction as it forms a stable hydrogen molecule from a very reactive hydrogen atom, and this reaction also competes with the most important chain-branching reaction R8, by consuming approximately $47 \%$ of the total concentration of $\dot{H}$ atoms, resulting in a reduced reactivity.

The other reactions inhibiting reactivity are termination reactions which involve consumption of $\dot{\mathrm{C}} \mathrm{H}_{3}$ radicals (mainly for the mixture of $1.75 \% \mathrm{DMC}$ ) by reactions $\mathrm{R} 12$ and $\mathrm{R} 13$, and very reactive $\dot{\mathrm{H}}$ atoms (mainly for the mixture of $0.75 \% \mathrm{DM}$ ) via reactions R14 and R15, to produce stable species.

$\dot{\mathrm{C}} \mathrm{H}_{3}+\mathrm{HO} \dot{\mathrm{O}}_{2} \rightleftarrows \mathrm{CH}_{4}+\mathrm{O}_{2}$

$\dot{\mathrm{C}} \mathrm{H}_{3}+\dot{\mathrm{C}} \mathrm{H}_{3}(+\mathrm{M}) \rightleftarrows \mathrm{C}_{2} \mathrm{H}_{6}(+\mathrm{M})$ 


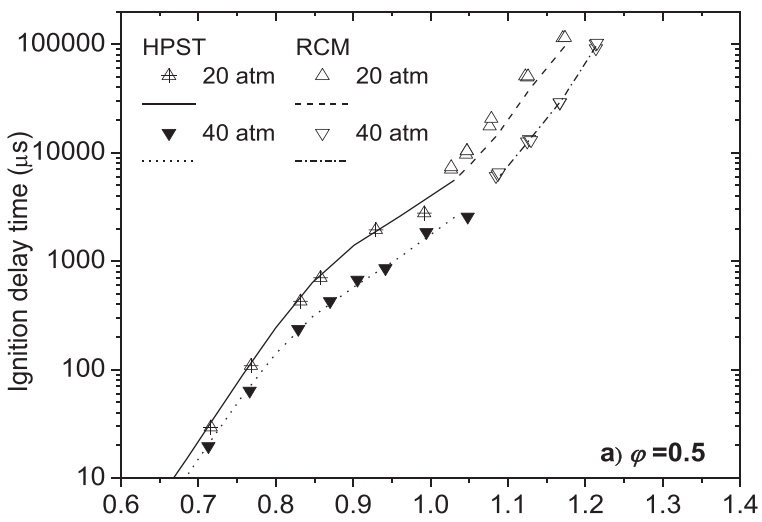

a) $\mathrm{T}=860 \mathrm{~K}$

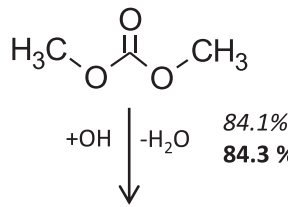
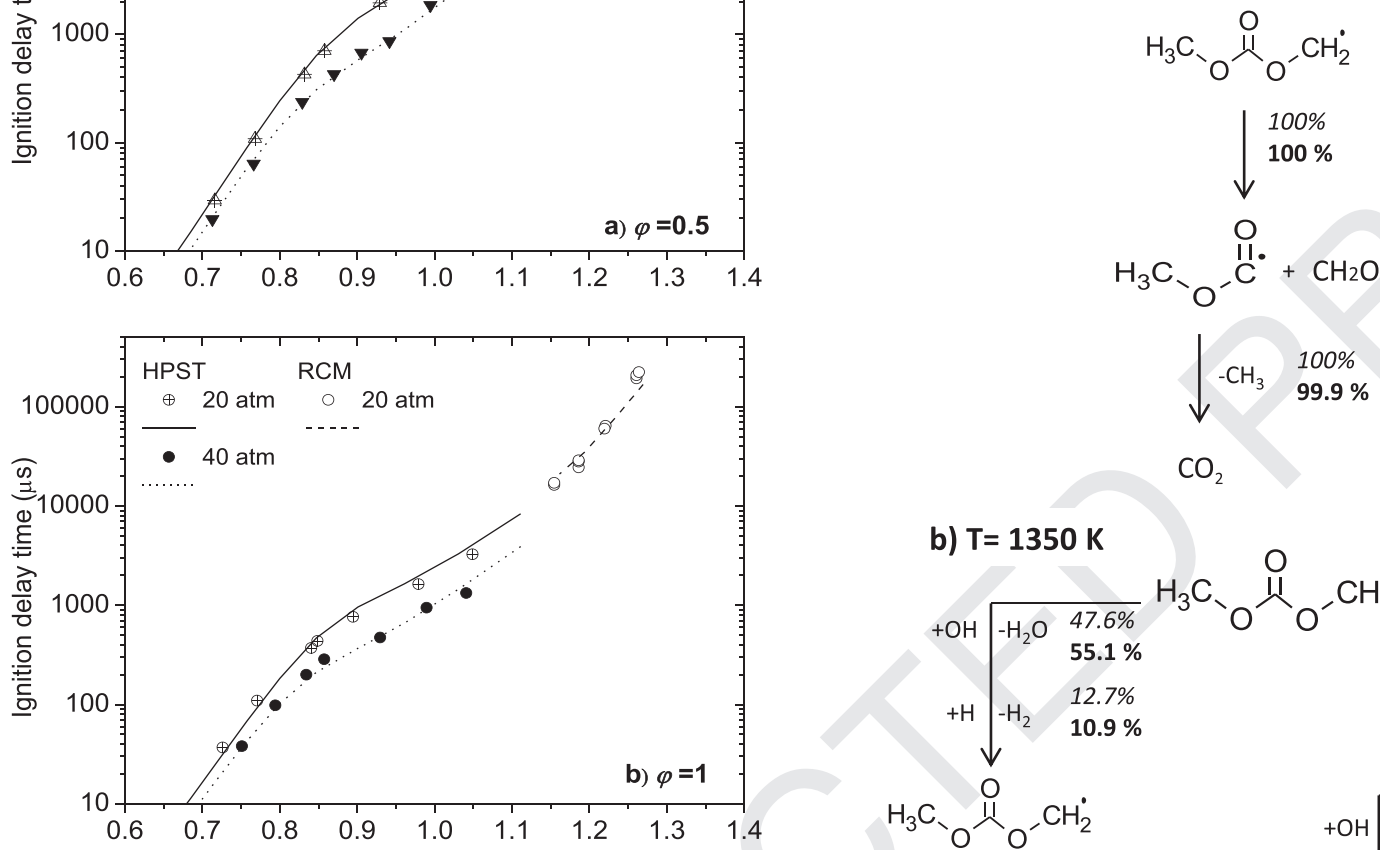

$\mathrm{CO}_{2}$

b) $\mathrm{T}=1350 \mathrm{~K}$

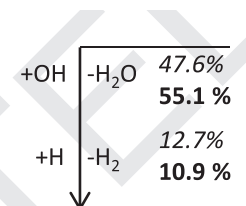

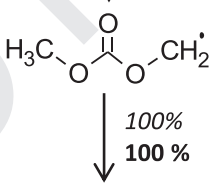<smiles>COC(=O)[14CH2][14CH]=O</smiles><smiles>COC(=O)OC</smiles>

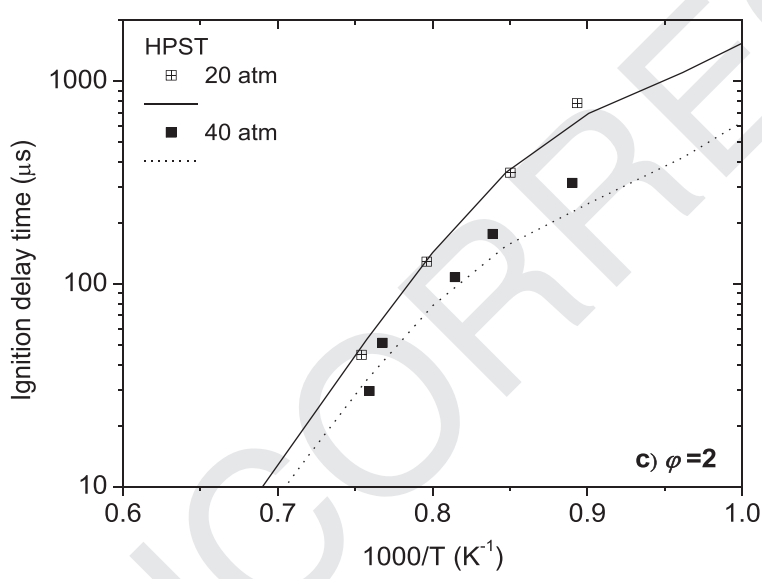

Fig. 14. Effect of the pressure on ignition delay times of DMC for $\varphi=0.5$ (mixtures $1 \mathrm{~B}, 4 \mathrm{~B}, 1 \mathrm{C}$ and $4 \mathrm{C}$ in Table 2), 1.0 (mixtures $2 \mathrm{~B}, 5 \mathrm{~B}$ and $2 \mathrm{C}$ in Table 2) and 2.0 (mixtures $3 \mathrm{~B}$ and $6 \mathrm{~B}$ in Table 2). Symbols: experimental data. Lines: AramcoMech2.0 + SunDMC_mod modeling.

$\mathrm{HO} \dot{\mathrm{O}}_{2}+\dot{\mathrm{H}} \rightleftarrows \mathrm{H}_{2}+\mathrm{O}_{2}$

$\dot{\mathrm{C}} \mathrm{H}_{3}+\dot{\mathrm{H}}(+\mathrm{M}) \rightleftarrows \mathrm{CH}_{4}(+\mathrm{M})$

\subsubsection{Effect of the pressure}

Figure 14 shows the effect of pressure on DMC ignition delay times at all three equivalence ratios studied (mixtures $1 \mathrm{~B}-6 \mathrm{~B}$ and, 1C, $2 \mathrm{C}$ and $4 \mathrm{C}$ in Table 2). No ignition was observed with the fuelrich mixture compressed at $20 \mathrm{~atm}$ in the RCM (3C in Table 2) and, as mentioned in Section 2, experiments with stoichiometric and fuel-rich mixtures compressed to $40 \mathrm{~atm}$ could not be performed in the RCM.

The ignition delay time decreases with increasing pressure at all equivalence ratios, with a more pronounced pressure effect at
Fig. 15. Reaction pathway analysis at a) $T=860 \mathrm{~K}$ and b) $T=1350 \mathrm{~K}$ for $P=20$ (italic font) and $40 \mathrm{~atm}$ (bold font), $\varphi=0.5$. Carried out at $20 \%$ fuel consumption.

temperatures below approximately $1250 \mathrm{~K}$. This increase in reactivity with increasing pressure is expected as at higher pressures the absolute concentration of reactants increases, thereby increasing the reaction rate.

Rate of production/ROP and sensitivity analyses were performed at $860 \mathrm{~K}$ and $1350 \mathrm{~K}$ for 20 and $40 \mathrm{~atm}, \varphi=0.5$, and are shown in Figs. 15 and 16, respectively. The analyses were carried out at low $(860 \mathrm{~K})$ and high $(1350 \mathrm{~K})$ temperature to account for the largest difference in ignition delay times observed at temperatures below $1250 \mathrm{~K}$.

As shown in Fig. 15, at a given temperature, the main reaction pathways for DMC consumption are the same at both pressures. However, there are differences in these at low and high temperatures. At high pressures and temperatures (Fig. 15b), the reaction flux resembles that at low pressures and high temperatures (Fig. 12), with the difference being that, at high pressure the unimolecular fuel decomposition reaction R1 is not important while $\mathrm{H}$-atom abstraction reactions are important. $\mathrm{H}$-atom abstraction from DMC, mostly by $\mathrm{OH}$ radicals, is the dominant pathway consuming DMC at both pressures, being slightly higher at $40 \mathrm{~atm}$ compared to $20 \mathrm{~atm}$ (55.1\% and $47.6 \%$, respectively). On the other hand, at high pressures and low temperatures (Fig. 15a), fuel consumption is controlled by $\mathrm{H}$-atom abstraction reactions by $\mathrm{OH}$ 


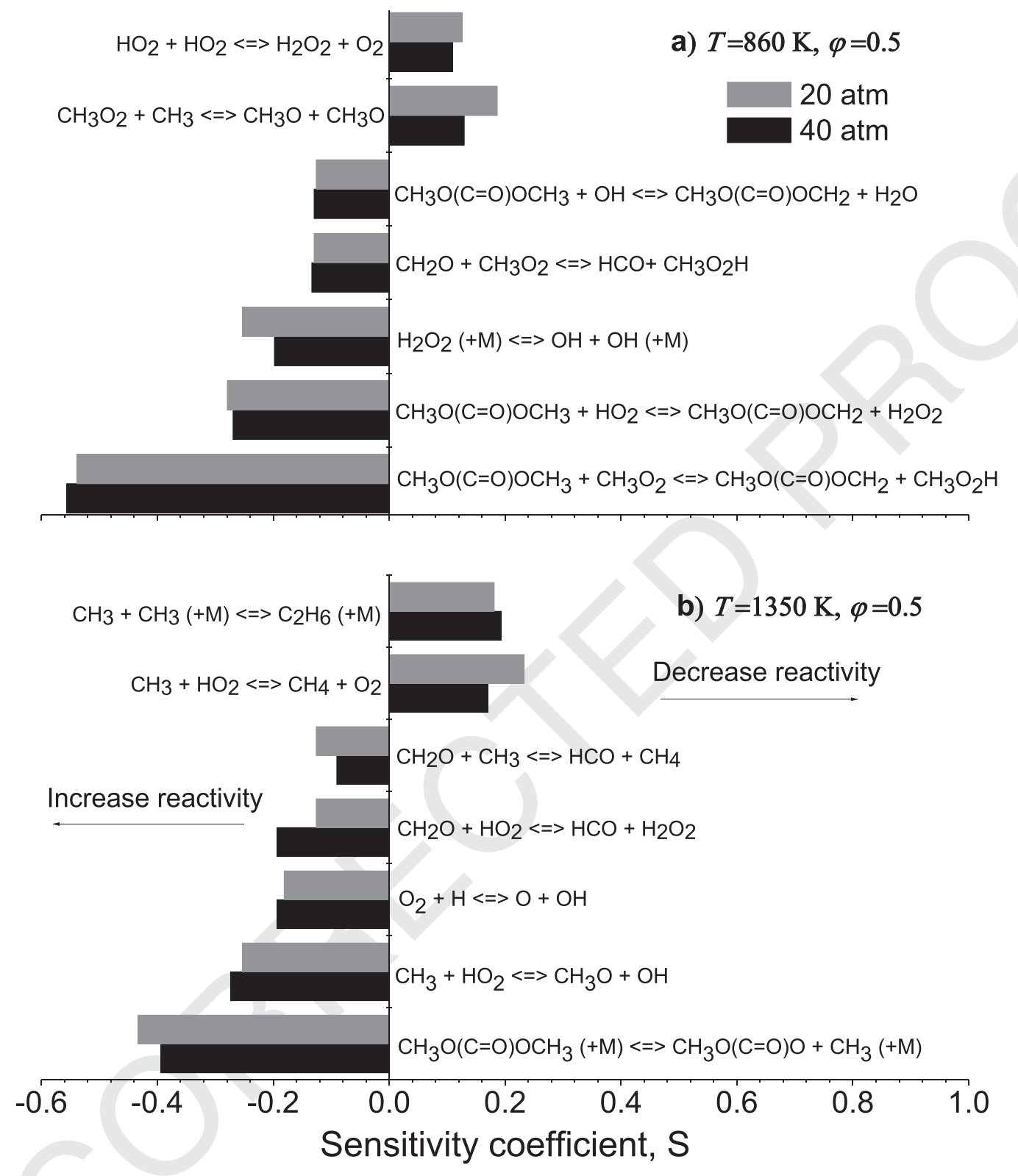

Fig. 16. Sensitivity analysis at a) $T=860 \mathrm{~K}$ and b) $T=1350 \mathrm{~K}$ for $P=20$ and 40 atm, $\varphi=0.5$.

radicals, with the percentage of DMC consumption being almost the same at both pressures $(84.1 \%$ and $84.3 \%$ at 20 atm and 40 atm, respectively).

Figure 16 indicates that, at a given temperature, the reactions controlling reactivity are the same at both pressures, which suggests that the decrease in ignition delay time with increasing pressure, observed in Fig. 14, is largely due to the increase in absolute concentration of reactants (DMC and $\mathrm{O}_{2}$ ) at higher pressure, rather than to a change in the controlling chemistry. However, the reactions controlling the reactivity at low and high temperatures are completely different.

At low temperatures $(860 \mathrm{~K}$, Fig. 16a), there are three fuelspecific reactions (R16, R17, and R18) that strongly promote reactivity.

$$
\begin{aligned}
& \mathrm{CH}_{3} \mathrm{O}(\mathrm{C}=\mathrm{O}) \mathrm{OCH}_{3}+\mathrm{CH}_{3} \dot{\mathrm{O}}_{2} \rightleftarrows \mathrm{CH}_{3} \mathrm{O}(\mathrm{C}=\mathrm{O}) \dot{\mathrm{C}}_{2}+\mathrm{CH}_{3} \mathrm{O}_{2} \mathrm{H} \\
& \mathrm{CH}_{3} \mathrm{O}(\mathrm{C}=\mathrm{O}) \mathrm{OCH}_{3}+\mathrm{HO}_{2} \rightleftarrows \mathrm{CH}_{3} \mathrm{O}(\mathrm{C}=\mathrm{O}) \dot{\mathrm{C}}_{2}+\mathrm{H}_{2} \mathrm{O}_{2} \\
& \mathrm{CH}_{3} \mathrm{O}(\mathrm{C}=\mathrm{O}) \mathrm{OCH}_{3}+\dot{\mathrm{OH}} \rightleftarrows \mathrm{CH}_{3} \mathrm{O}(\mathrm{C}=\mathrm{O}) \mathrm{OC} \mathrm{CH}_{2}+\mathrm{H}_{2} \mathrm{O}
\end{aligned}
$$

The $\mathrm{CH}_{3} \mathrm{O}(\mathrm{C}=\mathrm{O}) \mathrm{OC}_{2}$ radicals formed from these three re- 589 actions can further decompose to produce formaldehyde and 590 $\mathrm{CH}_{3} \mathrm{OC}=\mathrm{O}$ radicals (reaction $\mathrm{R} 6$ ), which in turn decompose to pro- 591 duce $\dot{\mathrm{C}} \mathrm{H}_{3}$ radicals and $\mathrm{CO}_{2}$ (reaction R7). Moreover, the $\mathrm{CH}_{3} \mathrm{O}_{2} \mathrm{H} 592$ and hydrogen peroxide $\left(\mathrm{H}_{2} \mathrm{O}_{2}\right)$ molecules formed, decompose to 593 form one and two $\dot{O} H$ radicals through reactions R19 and R20, fur- 594 ther promoting reactivity.

$\mathrm{CH}_{3} \mathrm{O}_{2} \mathrm{H} \rightleftarrows \mathrm{CH}_{3} \dot{\mathrm{O}}+\dot{\mathrm{O}} \mathrm{H}$

$\mathrm{H}_{2} \mathrm{O}_{2}(+\mathrm{M}) \rightleftarrows \dot{\mathrm{OH}}+\dot{\mathrm{O}} \mathrm{H}(+\mathrm{M})$

Thus, for each molecule of fuel that reacts with methylperoxy 596 $\left(\mathrm{CH}_{3} \mathrm{O}_{2}\right)$ and hydroperoxyl $\left(\mathrm{HO}_{2}\right)$ radicals, one and two $\dot{\mathrm{OH}}$ radicals 597 are formed, respectively. This greatly promotes reactivity because, 598 as previously discussed in relation to Fig. 15, the main path for 599 DMC consumption at high pressures is $\mathrm{H}$-atom abstraction by $\mathrm{OH} \quad 600$ radicals, which in turn also promotes reactivity at high pressures 601 and low temperatures (Fig. 16a). 

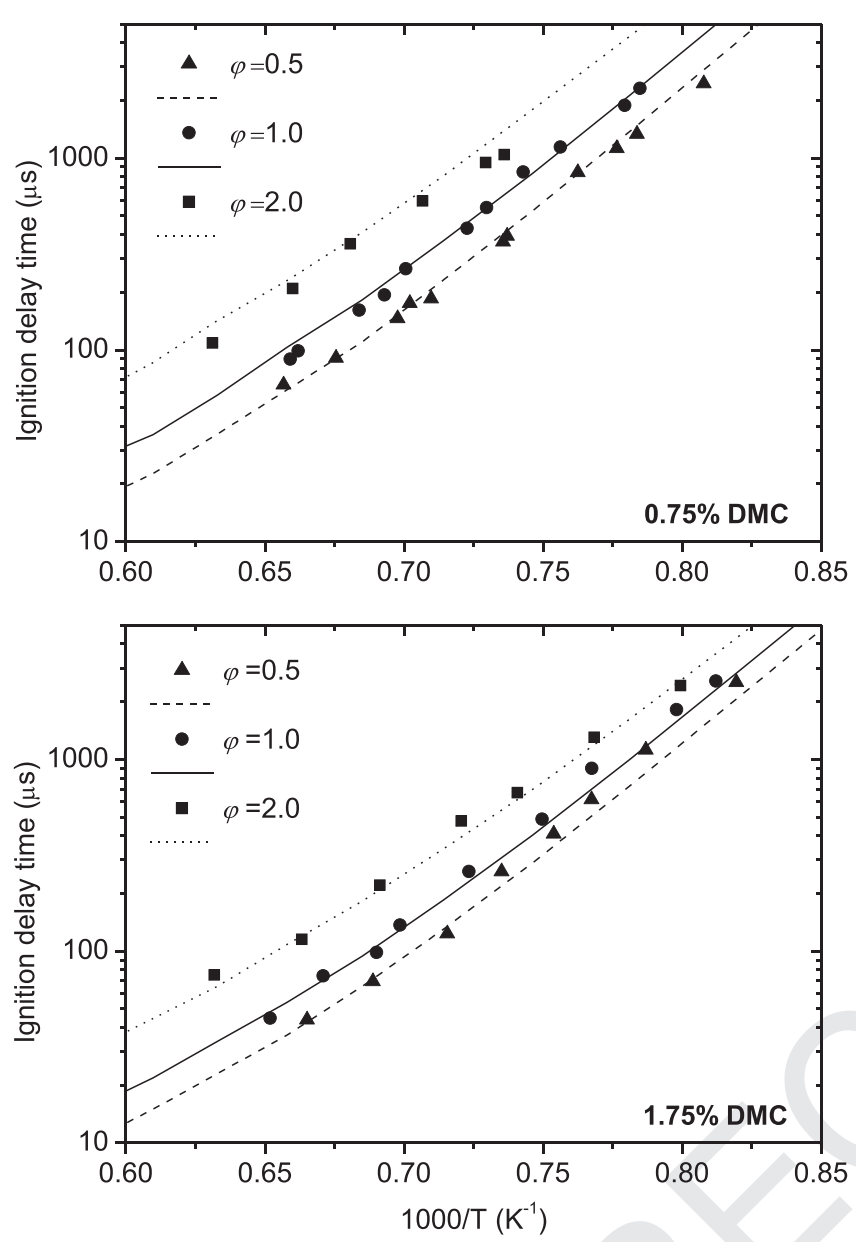

Fig. 17. Effect of equivalence ratio on ignition delay times of a) $0.75 \% \mathrm{DMC}$ and b) $1.75 \%$ DMC at $P=2 \mathrm{~atm}$ (Mixtures $1 \mathrm{~A}-6 \mathrm{~A}$ in Table 1). Symbols: experimental data. Lines: AramcoMech2.0 + SunDMC_mod modeling.

Another reaction that promotes the formation of $\mathrm{OH}$ radicals and hence increases reactivity, is the reaction of formaldehyde with the $\mathrm{CH}_{3} \dot{\mathrm{O}}_{2}$ radicals to produce $\mathrm{HCO}$ radicals and $\mathrm{CH}_{3} \mathrm{O}_{2} \mathrm{H}$ molecules. This promotes reactivity because it leads to the formation of $\dot{\mathrm{OH}}$ radicals through (1) the decomposition of the $\mathrm{CH}_{3} \mathrm{O}_{2} \mathrm{H}$ molecules (reaction R19), and (2) the reaction of the HCंO radicals with molecular oxygen by the following reaction sequence:

$\mathrm{HC} \mathrm{O}+\mathrm{O}_{2} \rightleftarrows \mathrm{CO}+\mathrm{HO}_{2}$

$\mathrm{HO}_{2}+\mathrm{HO}_{2} \rightleftarrows \mathrm{H}_{2} \mathrm{O}_{2}+\mathrm{O}_{2}$

Thereafter the $\mathrm{H}_{2} \mathrm{O}_{2}$ molecules decompose via reaction R20, leading to the formation of two $\dot{\mathrm{OH}}$ radicals.

As it is observed in Fig. 16a, reaction R22 inhibits reactivity because this termination reaction competes with $\mathrm{H}$-atom abstraction from DMC (reaction R17). If $\mathrm{HO}_{2}$ radicals react with DMC instead of reacting with each other, two $\mathrm{H}_{2} \mathrm{O}_{2}$ molecules can be formed (through reaction R17), ultimately leading to the formation of four $\dot{\mathrm{OH}}$ radicals (through reaction R20), thereby increasing reactivity.

The other reaction that inhibits reactivity is the termination reaction of $\mathrm{CH}_{3} \dot{\mathrm{O}}_{2}$ with methyl radicals to produce two $\mathrm{CH}_{3} \mathrm{O}$ radicals. In this way, $\mathrm{CH}_{3} \mathrm{O}_{2}$ radicals are consumed to produce stable species instead of reacting with DMC (by reaction R16) to further form the $\mathrm{OH}$ radicals through the decomposition of $\mathrm{CH}_{3} \mathrm{O}_{2} \mathrm{H}$ molecules (reaction R19).
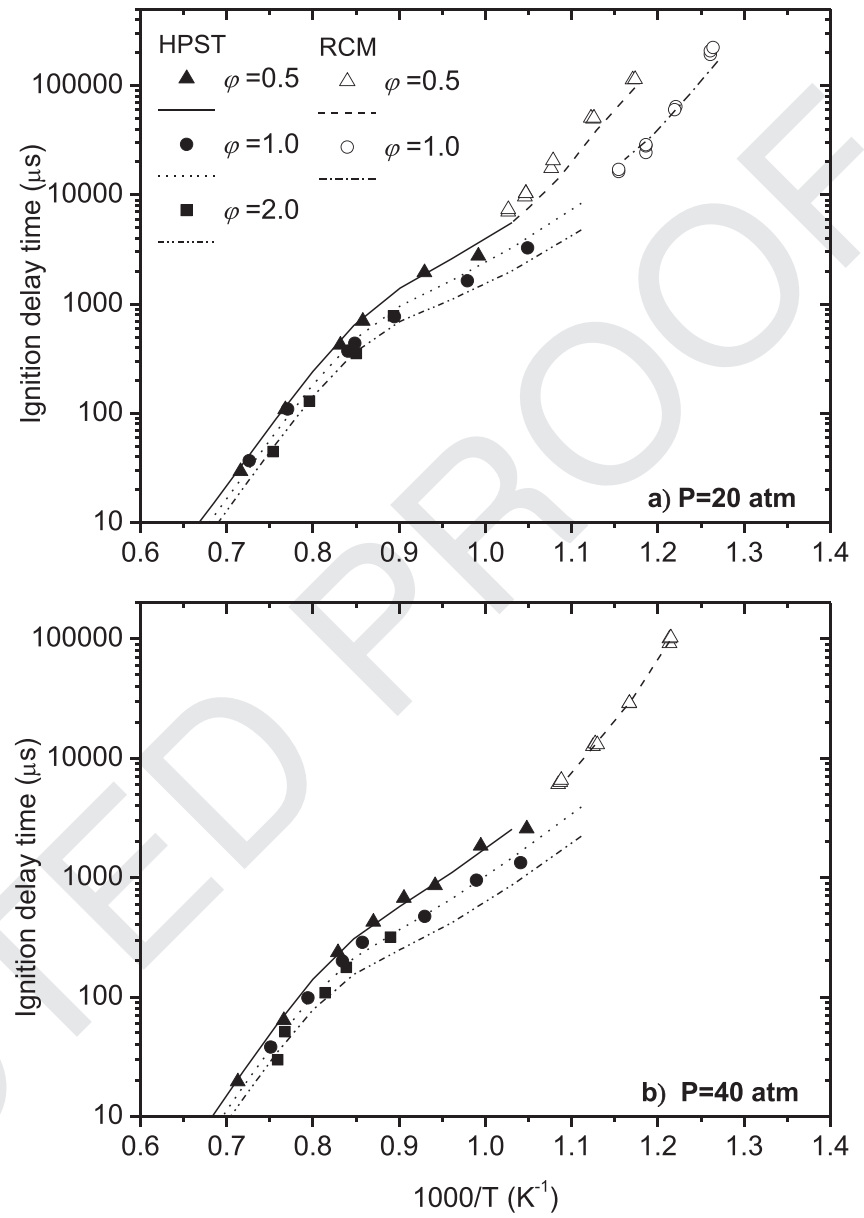

Fig. 18. Effect of equivalence ratio on ignition delay time of DMC at $P=20$ and $40 \mathrm{~atm}$ (Mixtures $1 \mathrm{~B}-6 \mathrm{~B}$ and $1 \mathrm{C}, 2 \mathrm{C}$ and $4 \mathrm{C}$ in Table 2). Symbols: experimental data. Lines: AramcoMech2.0 + SunDMC_mod modeling.

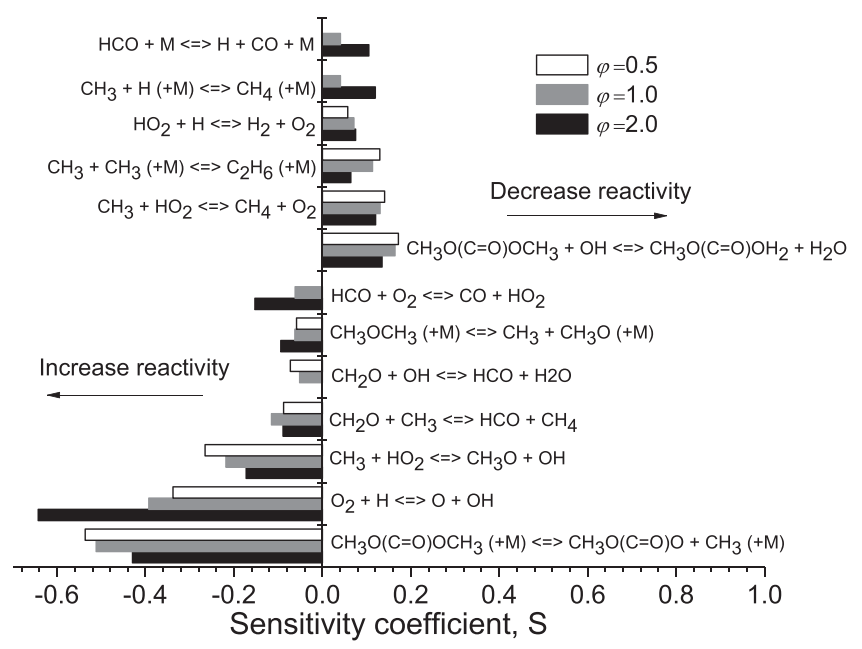

Fig. 19. Sensitivity analysis for $\varphi=0.5,1.0$, and $2.0,1.75 \% \mathrm{DMC}, P=2$ atm at $T=1350 \mathrm{~K}$.

The sensitivity coefficients of these two inhibiting reactions increase with decreasing pressure, indicating that these two reactions are more dominant at lower pressures.

At high temperatures $(1350 \mathrm{~K}$, Fig. 16b), most of the reactions promoting and inhibiting reactivity are similar to those discussed above in Fig. 13. Reaction R1 leads to the formation of $\dot{\mathrm{C}} \mathrm{H}_{3}$ radicals which promotes reactivity, since they react with hydroperoxyl 


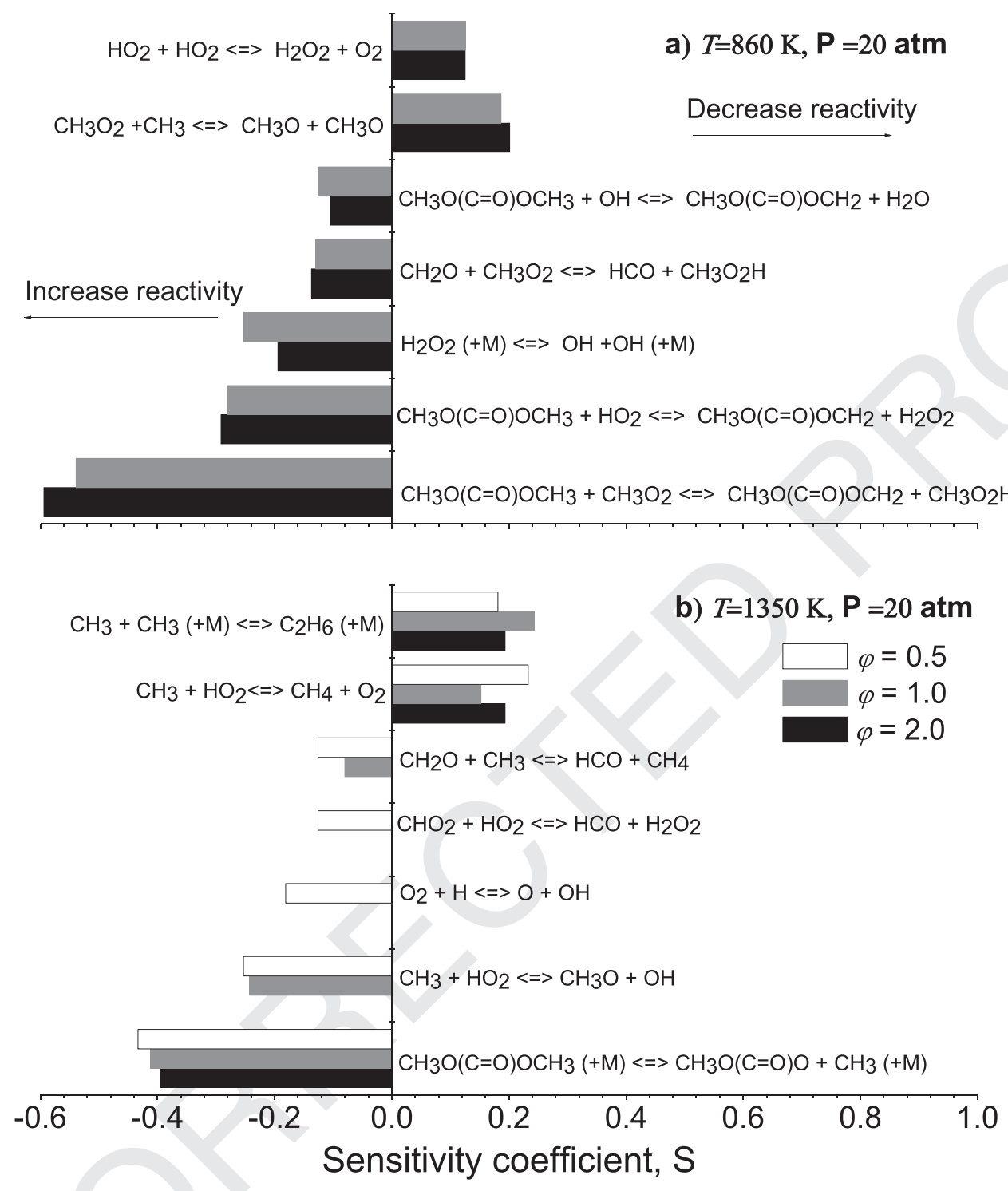

Fig. 20. Sensitivity analysis at a) $T=860 \mathrm{~K}$ and b) $T=1350 \mathrm{~K}$, for $P=20 \mathrm{~atm}, \varphi=0.5,1.0$, and 2.0.

radicals to produce $\mathrm{CH}_{3} \dot{\mathrm{O}}$ radicals and highly reactive $\dot{\mathrm{O}} \mathrm{H}$ radicals (reaction $\mathrm{R} 9$ ). The other reactions promoting reactivity also involve the formation of $\dot{\mathrm{OH}}$ radicals directly or by $\mathrm{H}_{2} \mathrm{O}_{2}$ molecules and $\mathrm{HC} \mathrm{O}$ radicals as intermediates to ultimately produce $\dot{\mathrm{O}} \mathrm{H}$ radicals by reactions R20-R22. On the other hand, the reaction between $\dot{\mathrm{C}} \mathrm{H}_{3}$ and $\mathrm{HO}_{2}$ radicals (reaction R12) and the recombination of two $\dot{\mathrm{C}} \mathrm{H}_{3}$ radicals to produce ethane (reaction R13) decrease reactivity because these are chain-termination reactions and compete with the promoting reaction $\mathrm{R} 9$.

The largest difference on the ignition delay times, observed between the two pressures at temperatures below $1250 \mathrm{~K}$, is attributed to the fact that at low temperatures the system reactivity is highly controlled by reactions that involve fuel consumption (reactions R16-R18), thus the effect of increasing DMC concentration, due to the increase in pressure, is more noticeable than at high temperatures.

\subsubsection{Effect of the equivalence ratio}

The equivalence ratio dependence was also analyzed for low (2 atm) and high pressures (20 and $40 \mathrm{~atm}$ ). Figure 17 shows that, at $2 \mathrm{~atm}$ at both DMC concentrations, ignition delay times decrease, i.e. reactivity increases with decreasing equivalence ra- tio (increasing $\mathrm{O}_{2}$ fraction) at all temperatures investigated, with 652 the fuel-lean mixture being the most reactive. Conversely, at high 653 pressures reactivity increases with increasing equivalence ratio, as 654 shown in Fig. 18. This tendency is more prominent at lower tem- 655 peratures indicating that DMC shows different equivalence ratio 656 sensitivities at different temperatures.

In order to analyze the equivalence ratio sensitives of igni- 658 tion delay time under different equivalence ratio at low (2 atm) 659 and high $(20 \mathrm{~atm})$ pressure, a sensitivity analysis is shown in 660 Figs. 19 and 20, respectively. The high pressure sensitivity analysis 661 (Fig. 20) was performed at low $(860 \mathrm{~K})$ and high $(1350 \mathrm{~K})$ tempera- 662 ture to account for the largest difference on the ignition delay time 663 observed in the lower temperature regime.

It is highlighted that at low pressure (Fig. motes reactivity (decreases ignition delay times), while at high 666 pressure (Fig. 20), reactions involving DMC consumption are more 667 important in promoting reactivity (reactions R16-R18 for low tem- 668 perature and reaction R1 for high temperature) instead of reac- 669 tion R8. Consequently, the fuel-lean mixture is more reactive at 670 low pressures (Fig. 17) due to its higher oxygen content which 671 leads to a higher reaction rate of reaction R8. On the other hand, 672 the fuel-rich mixture is more reactive at high pressures (Fig. 18) 673 
because its higher DMC content leads to a higher reaction rate of the fuel-specific reactions. The largest difference in reactivity is in the lower temperature regime since, as seen in Fig. 20, there are more fuel-specific reactions promoting reactivity at low temperatures (Fig. 20a) than at high temperatures (Fig. 20b).

\section{Conclusions}

This work presents ignition delay time measurements of $\mathrm{DMC} / \mathrm{O}_{2} / \mathrm{Ar}$ and $\mathrm{DMC} / \mathrm{O}_{2} /$ air mixtures in low- and high-pressure shock tubes and in a rapid compression machine. Investigation of the effects of some experimental parameters such as, DMC concentration ( $0.75 \%$ and $1.75 \%)$, equivalence ratio $(0.5,1.0$, and 2.0$)$, and reflected shock temperature (795-1585 K) and pressure (2.0, 20 , and $40 \mathrm{~atm}$ ) were performed to further understand the low and high temperature and pressure behavior of DMC oxidation.

The performance of four models from the literature in predicting the present experimental data was analyzed, followed by the study of the effect of the thermodynamic of the $\mathrm{CH}_{3} \mathrm{O}(\mathrm{C}=\mathrm{O}) \mathrm{O}$ radical species on ignition delay time calculations. It was observed that, depending on the rate constant for the fuel decomposition reaction $\mathrm{CH}_{3} \mathrm{O}(\mathrm{C}=\mathrm{O}) \mathrm{OCH}_{3} \rightleftarrows \mathrm{CH}_{3} \mathrm{O}(\mathrm{C}=\mathrm{O}) \dot{\mathrm{O}}+\dot{\mathrm{CH}}_{3}$, the thermodynamics of the $\mathrm{CH}_{3} \mathrm{O}(\mathrm{C}=\mathrm{O}) \mathrm{O}$ radical species have an effect on the ignition delay times at high temperatures, at both lowand high-pressures. The effect of the reaction $\mathrm{CH}_{3} \mathrm{O}(\mathrm{C}=\mathrm{O}) \mathrm{OCH}_{3} \rightleftarrows$ $\mathrm{CH}_{3} \mathrm{O}(\mathrm{C}=\mathrm{O}) \dot{\mathrm{O}}+\dot{\mathrm{CH}}_{3}$ on the calculations of ignition delay times was also analyzed.

A final model, Aramco2.0+SunDMC_mod, whose calculations showed good agreement with the ignition delay time measurements from this work, was used to perform reaction path and sensitivity analyses to determine the most important reactions controlling DMC oxidation over the wide range of conditions studied. This model was also used to calculate the concentration profiles of species measured in flow reactors, and opposed flow diffusion and laminar premixed flames showing satisfactory predictions of the experimental results.

The kinetic study showed that reactivity of the system (reduction of the ignition delay time) increases with an increase in DMC concentration and in pressure due to the increase in reactant concentrations. On the other hand, the influence of the equivalence ratio depends on pressure; at low pressures reactivity increases with decreasing equivalence ratio, while at high pressures reactivity increases with increasing equivalence ratio. This is because, at low pressures, reactivity is mainly due to the reaction $\dot{\mathrm{H}}+\mathrm{O}_{2} \rightleftarrows \ddot{\mathrm{O}}+\dot{\mathrm{O}} \mathrm{H}$, and thus the lower the equivalence ratio (increasing $\mathrm{O}_{2}$ fraction), the higher is the rate of this chain-branching reaction. On the contrary, at high pressures the reactivity of the system is promoted by fuel-specific reactions $\left(\mathrm{CH}_{3} \mathrm{O}(\mathrm{C}=\mathrm{O}) \mathrm{OCH}_{3}+\mathrm{CH}_{3} \mathrm{O}_{2} \rightleftarrows \mathrm{CH}_{3} \mathrm{O}(\mathrm{C}=\mathrm{O}) \mathrm{OCH}_{2}+\mathrm{CH}_{3} \mathrm{O}_{2} \mathrm{H}\right.$; $\mathrm{CH}_{3} \mathrm{O}(\mathrm{C}=\mathrm{O}) \mathrm{OCH}_{3}+\mathrm{HO}_{2} \rightleftarrows \mathrm{CH}_{3} \mathrm{O}(\mathrm{C}=\mathrm{O}) \mathrm{OCH}_{2}+\mathrm{H}_{2} \mathrm{O}_{2} ;$ and $\mathrm{CH}_{3} \mathrm{O}(\mathrm{C}=\mathrm{O}) \mathrm{OCH}_{3}+\dot{\mathrm{OH}} \rightleftarrows \mathrm{CH}_{3} \mathrm{O}(\mathrm{C}=\mathrm{O}) \mathrm{OCH}_{2}+\mathrm{H}_{2} \mathrm{O}$ for low temperature, and $\mathrm{CH}_{3} \mathrm{O}(\mathrm{C}=\mathrm{O}) \mathrm{OCH}_{3}(+\mathrm{M}) \rightleftarrows \mathrm{CH}_{3} \mathrm{O}(\mathrm{C}=\mathrm{O}) \mathrm{O}+\mathrm{CH}_{3}$ for high temperature), thus higher equivalence ratio (increasing fuel concentrations) lead to higher reactivity. At high pressures, the influence of pressure and equivalence ratio on ignition delay times is more prominent at low temperatures because a large number of fuel-specific reactions promote reactivity in this regime.

\section{Acknowledgments}

The authors acknowledge the financial support of Saudi Aramco for the research reported in this publication and to MINECO (EEBBI-16-11445, CTQ2015-65226). K. Alexandrino also acknowledges MINECO for the pre-doctoral Grant awarded (BES-2013-063049).

\section{Supplementary materials}

Supplementary material associated with this article can be found, in the online version, at doi:10.1016/j.combustflame.2017.10. 001.

\section{References}

[1] G.D. Zhang, H. Liu, X.X. Xia, W.G. Zhang, J.H. Fang, Effects of dimethyl carbonate fuel additive on diesel engine performances, Proc. Inst. Eng. Part D - J. Automob. Eng. 219 (2005) 897-903.

[2] C.S. Cheung, S.C. Lee, A.K. Mphil, C.W. Tung, Effect of dimethyl carbonate blended diesel on emissions of a 4-cylinder diesel engine, HKI Trans. 12 (2014) $15-20$.

[3] C.S. Cheung, R. Zhu, Z. Huang, Investigation on the gaseous and particulate emissions of a compression ignition engine fueled with diesel-dimethyl carbonate blends, Sci. Total Environ. 409 (2011) 523-529.

[4] M.H.J. Wijnen, Decomposition of dimethyl carbonate on quartz, J. Chem. Phys. 34 (1961) 1465-1466.

[5] J.C.J. Thynne, P. Gray, The methyl-radical-sensitized decomposition of gaseous dimethyl carbonate, Trans. Faraday Soc. 58 (1962) 2403-2409.

[6] J.T.D. Cross, R. Hunter, V.R. Stimson, The thermal decomposition of simple carbonate esters, Aust. J. Chem. 29 (1976) 1477-1481.

[7] M.J.Y. Quee, J.C.J. Thynne, Photolysis of dimethyl carbonate, Trans. Faraday Soc 62 (1966) 3154-3161.

[8] A. Sinha, M.J. Thomson, The chemical structures of opposed flow diffusion flames of C3 oxygenated hydrocarbons (isopropanol, dimethoxy methane, and dimethyl carbonate) and their mixtures, Combust. Flame 136 (2004) 548556.

[9] P.A. Glaude, W.J. Pitz, Murray J. Thomson, Chemical kinetic modeling of dimethyl carbonate in an opposed-flow diffusion flame, Proc. Combust. Inst. 30 (2005) 1111-1118.

[10] S.L. Fischer, F.L. Dryer, H.J. Curran, The reaction kinetics of dimethyl ether. I: high-temperature pyrolysis and oxidation in flow reactors, Int. J. Chem. Kinet 32 (2000) 713-740.

[11] H.J. Curran, Private communication (2002).

[12] G. Chen, W. Yu, J. Fu, J. Mo, Z. Huang, J. Yang, Z. Wang, H. Jin, F. Qi, Experimental and modeling study of the effects of adding oxygenated fuels to premixed n-heptane flames, 159 (2012) 2324-2335.

[13] S.L. Peukert, R. Sivaramakrishnan, J.V. Michael, High temperature shock tube and theoretical studies on the thermal decomposition of dimethyl carbonate and its bimolecular reactions with H and D-Atoms, J. Phys. Chem. A 117 (2013) 3718-3728.

[14] S. Peukert, R. Sivaramakrishnan, J. Michael, Shock tube and modeling study of the pyrolysis of dimethyl carbonate and its reaction with D-and O-atoms, 8th U. S. National Combustion Meeting (2013) Paper 070RK-0007.

[15] M.E. Bardin, E.V. Ivanov, E.J.K. Nilsson, V.A. Vinokurov, A.A. Konnov, Laminar burning velocities of dimethyl carbonate with air, Energy Fuels 27 (2013) 5513-5517.

[16] E. Hu, Y. Chen, Z. Zhang, L. Pan, Q. Li, Y. Cheng, Z. Huang, Experimental and kinetic study on ignition delay times of dimethyl carbonate at high temperature Fuel 140 (2015) 626-632.

[17] W.K. Metcalfe, S.M. Burke, S.S. Ahmed, H.J. Curran, A hierarchical and comparative kinetic modeling study of $\mathrm{C} 1-\mathrm{C} 2$ hydrocarbon and oxygenated fuels, Int J. Chem. Kinet. 45 (2013) 638-675.

[18] W. Sun, B. Yang, N. Hansen, C.K. Westbrook, F. Zhang, G. Wang, K. Moshammer, C.K. Law, An experimental and kinetic modeling study on dimethyl carbonate (DMC) pyrolysis and combustion, Combust. Flame 164 (2016) 224 238.

[19] M.U. Alzueta, P. Salinas, Á. Millera, R. Bilbao, M. Abián, A study of dimethy carbonate conversion and its impact to minimize soot and NO emissions, Proc. Combust. Int. 36 (2017) 3985-3993.

[20] P. Glarborg, M.U. Alzueta, K. Dam-Johansen, J.A. Miller, Kinetic modeling of hydrocarbon/nitric oxide interactions in a flow reactor, Combust. Flame 115 (1998) 1-27.

[21] M. Abián, C. Esarte, Á. Millera, R. Bilbao, M.U. Alzueta, Oxidation of acetyleneethanol mixtures and their interaction with NO, Energy Fuels 22 (2008) 38143823.

[22] M. Abián, J. Giménez-López, R. Bilbao, M.U. Alzueta, Effect of different concentration levels of $\mathrm{CO}_{2}$ and $\mathrm{H}_{2} \mathrm{O}$ on the oxidation of $\mathrm{CO}$ : experiments and modeling, Proc. Combust. Inst. 33 (2011) 317-323.

[23] M. Abián, Á. Millera, R. Bilbao, M.U. Alzueta, An experimental and modeling study of the influence of the gases recirculated on ethylene conversion, 161 (2014) 2288-2296.

[24] M. Abián, E. Peribáñez, Á. Millera, R. Bilbao, M.U. Alzueta, Impact of nitrogen oxides (NO, $\mathrm{NO}_{2}, \mathrm{~N}_{2} \mathrm{O}$ ) on the formation of soot, Combust. Flame 161 (2014) 280-287.

[25] K. Alexandrino, J. Salinas, Á. Millera, R. Bilbao, M.U. Alzueta, Sooting propensity of dimethyl carbonate, soot reactivity and characterization, Fuel 183 (2016) 6472.

[26] J.M. Smith, J.M. Simmie, H.J. Curran, Autoignition of heptanes; experiments and modeling, Int. J. Chem. Kinet. 37 (2005) 728-736.

[27] C. Morley, Gaseq, Version 0.76, 2004. Available at http://www.gaseq.co.uk (accessed 06.06.2017).

\section{8}

739

740

741

742 
[28] H. Nakamura, D. Darcy, M. Mehl, C.J. Tobin, W.K. Metcalfe, W.J. Pitz, C.K. Westbrook, H.J. Curran, An experimental and modeling study of shock tube and rapid compression machine ignition of $n$-butylbenzene/air mixtures, Combust. Flame 161 (2014) 49-64.

[29] A.R. Amadio, M.W. Crofton, E.L. Petersen, Test-time extension behind reflected shock waves using $\mathrm{CO}_{2}$ - $\mathrm{He}$ and $\mathrm{C}_{3} \mathrm{H}_{8}$-He driver mixtures, Shock Waves 16 (2006) 157-165.

30] D. Davidson, R.K. Hanson, Interpreting shock tube ignition data, Int. J. Chem. Kinet. 36 (2004) 510-523.

[31] D. Darcy, H. Nakamura, C.J. Tobin, M. Mehl, W.K. Metcalfe, W.J. Pitz, C.K. Westbrook, H.J. Curran, A high-pressure rapid compression machine study of npropylbenzene ignition, Combust. Flame 161 (2014) 65-74.

[32] Sung C-J, H.J. Curran, Using rapid compression machines for chemical kinetic models, Prog. Energy Combust. Sci. 44 (2014) 1-18.

[33] CHEMKIN-PRO 15131, Reaction Design, San Diego 2013.
[34] S. Dooley, H.J. Curran, J.M. Simmie, Autoignition measurements and a validated 830 kinetic model for the biodiesel surrogate, methyl butanoate, Combust. Flame 831 153 (2008) 2-32. phase radicals and molecules, Int. J. Chem. Kinet. 23 (1991) 767-778.

[36] Y. Georgievskii, J.A. Miller, M.P. Burke, S.J. Klippenstein, Reformulation and so- 835 lution of the master equation for multiple-well chemical reactions, J. Phys. 836 Chem. A 117 (2013) 12146-12154

[37] C.W. Zhou, Y. Li, E. O'Connor, K.P. Somers, S. Thion, C. Keesee, O. Mathieu, 838 E.L. Petersen, T.A. DeVerter, M.A. Oehlschlaeger, G. Kukkadapu, C. Sung, M. Al- 839 refae, F. Khaled, A. Farooq, P. Dirrenberger, P.A. Glaude, F. Battin-Leclerc, J. Sant- 840 ner, Y. Ju, T. Held, F.M. Haas, F.L. Dryer, H.J. Curran, A comprehensive experi- 841 mental and modeling study of isobutene oxidation, Combust. Flame 167 (2016) 842 353-379.. 